\title{
The Status of Clinical Faculty in the Legal Academy: Report of the Task Force on the Status of Clinicians and the Legal Academy
}

Kate Kruse

Mitchell Hamline School of Law, kate.kruse@mitchellhamline.edu

Bryan L. Adamson

Brad Colbert

Mitchell Hamline School of Law, brad.colbert@mitchellhamline.edu

Kathy Hessler

Publication Information

36 Journal of the Legal Profession 353 (2012)

\section{Repository Citation}

Kruse, Kate; Adamson, Bryan L.; Colbert, Brad; and Hessler, Kathy, "The Status of Clinical Faculty in the Legal Academy: Report of the Task Force on the Status of Clinicians and the Legal Academy" (2012). Faculty Scholarship. Paper 342.

http://open.mitchellhamline.edu/facsch/342 


\title{
The Status of Clinical Faculty in the Legal Academy: Report of the Task Force on the Status of Clinicians and the Legal Academy
}

\begin{abstract}
In the midst of ongoing debates within the legal academy and the American Bar Association on the need for "practice-ready" law school graduates through enhanced attention to law clinics and externships and on the status of faculty teaching in those courses, this report identifies and evaluates the most appropriate modes for clinical faculty appointments. Drawing on data collected through a survey of clinical program directors and faculty, the report analyzes the five most identifiable clinical faculty models: unitary tenure track; clinical tenure track; long-term contract; short-term contract; and clinical fellowships. It determines that, despite great strides in the growth of clinical legal education in the last 30 years, equality between clinical and nonclinical faculty remains elusive. Clinical faculty still lag behind non-clinical faculty in security of position and governance rights at most law schools.
\end{abstract}

The report then identifies four core principles that should guide decisions about clinical faculty appointments: 1) clinical education is a foundational and essential component of legal education; 2 ) the legal academy and profession benefit from full inclusion of clinical faculty on all matters affecting the mission, function, and direction of law schools; 3 ) there is no justification for creating hierarchies between clinical and non-clinical faculty; and 4) the standards for hiring, retention, and promotion of clinical faculty must recognize and value the responsibilities and methodologies of clinical teaching.

The report concludes that these core principles are best realized when full-time clinical faculty are appointed to a unitary tenure track. This conclusion does not ignore the imperfections of a tenure system. However, to the extent that tenure remains the strongest measure of the legal academy's investment in its faculty and is the surest guarantee of academic freedom, inclusion in faculty governance and job security, the report recommends that law schools predominantly place their clinical faculty on dedicated tenure lines. In addition, it recommends that schools implement standards for hiring, promotion, and retention that reflect the teaching responsibilities and methodologies, as well as practice and service obligations, unique to their clinical faculty. To facilitate the development of such standards, the report suggests good practices for the appointment of clinical faculty on a unitary tenure track.

Keywords

Legal consultants, Law schools, Academic tenure, Clinical legal education, Law--Study and teaching

\author{
Disciplines \\ Legal Education
}




\section{The Status of CliniCAL FaCUlty in the LeGaL ACADEMY: REPORT OF THE TASK FORCE ON THE STATUS OF CLINICIANS AND THE LEGAL ACADEMY}

By Bryan L. Adamson, Bradford Colbert, Kathy Hessler, Katherine Kruse, Robert Kuehn, Mary Helen McNeal, Calvin Pang \& David Santacroce*

\section{ABSTRACT}

In the midst of ongoing debates within the legal academy and the American Bar Association on the need for "practice-ready" law school graduates through enhanced attention to law clinics and externships and on the status of faculty teaching in those courses, this report identifies and evaluates the most appropriate modes for clinical faculty appointments. Drawing on data collected through a survey of clinical program directors and faculty, the report analyzes the five most identifiable clinical faculty models: unitary tenure track; clinical tenure track; long-term contract; short-term contract; and clinical fellowships. It determines that, despite great strides in the growth of clinical legal education in the last 30 years, equality between clinical and non-clinical faculty remains elusive. Clinical faculty still lag behind non-clinical faculty in security of position and governance rights at most law schools.

The report then identifies four core principles that should guide decisions about clinical faculty appointments: 1) clinical education is a foundational and essential component of legal education; 2) the legal academy and profession benefit from full inclusion of clinical faculty on all matters affecting the mission, function, and direction of law schools; 3) there is no justification for creating hierarchies between clinical and non-clinical faculty; and 4) the standards for

\footnotetext{
* Disclaimer in accordance with American Association of Law Schools (AALS) Executive Committee Regulation 1.4: The opinions and recommendations expressed in this Report are not necessarily those of the Section on Clinical Legal Education and do not necessarily represent the position of the AALS.
} 
hiring, retention, and promotion of clinical faculty must recognize and value the responsibilities and methodologies of clinical teaching.

The report concludes that these core principles are best realized when full-time clinical faculty are appointed to a unitary tenure track. This conclusion does not ignore the imperfections of a tenure system. However, to the extent that tenure remains the strongest measure of the legal academy's investment in its faculty and is the surest guarantee of academic freedom, inclusion in faculty governance and job security, the report recommends that law schools predominantly place their clinical faculty on dedicated tenure lines. In addition, it recommends that schools implement standards for hiring, promotion, and retention that reflect the teaching responsibilities and methodologies, as well as practice and service obligations, unique to their clinical faculty. To facilitate the development of such standards, the report suggests good practices for the appointment of clinical faculty on a unitary tenure track.

INTRODUCTION 356

I.CLINICAL FACULTY IN THE LEGAL ACADEMY 363

A. THE NATURE OF CLINICAL LEGAL EDUCATION..........363

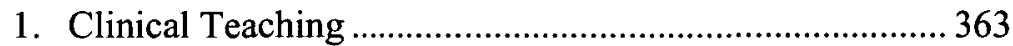

2. The Social Justice Mission of Clinical Legal Education... 367

3. Scholarship by Clinical Faculty ........................................... 369

B. ABA REGULATION OF CLINICAL FACULTY

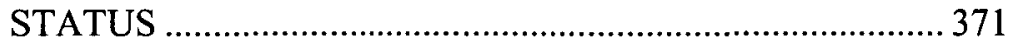

C. FIVE MODELS OF CLINICAL FACULTY STATUS ...........372

1. Unitary Tenure-Track........................................................ 373

2. Clinical Tenure-Track ................................................... 374

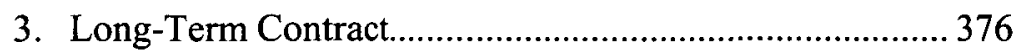

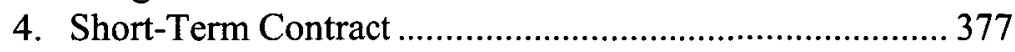

5. Clinical Fellowships..................................................... 378

II.CORE PRINCIPLES AND RECOMMENDATIONS ......................... 379

A. CORE PRINCIPLES .............................................................. 380

1. Clinical Education Is A Foundational And Essential Component Of Legal Education.

2. The Legal Academy And Profession Benefit From The Full Inclusion Of Clinical Faculty On All Matters Affecting The Mission, Function, And Direction Of The Law School.

3. There Is No Justification For Creating Hierarchies Between Clinical And Non- Clinical Faculty. 
4. The Standards For Hiring, Retention, And Promotion Of Clinical Faculty Must Recognize And Value The Responsibilities And Methodologies Of Clinical Teaching.

B. TASK FORCE RECOMMENDATIONS 388

1. The Benefits Of Clinical Legal Education Are Best Achieved By Predominantly Employing Full-Time Clinical Faculty On A Unitary Tenure Track That Recognizes And Values The Responsibilities And Methodologies Of Clinical Law Teaching.

2. Separate Clinical Tenure And Long-Term Contract Models Are Inferior Because They Have Usually Resulted In A Permanent And Unequal Class Of Faculty Members With Less Secure Job Status And Diminished Governance Rights.

3. Short-Term Contracts And Clinical Fellowships Should Be Reserved For Limited Situations Tailored To The Purposes That They Are Best Designed To Serve.

III. TENSIONS REGARDING THE UNITARY TENURE-TRACK MODEL FOR CLINICAL FACULTY

A. TENURE AND REGULATION OF THE SECURITY OF POSITION

B. COSTS

C. CLINICAL FACULTY SCHOLARSHIP 398

D. ACADEMIC FREEDOM PROTECTIONS IN CLINICAL LEGAL EDUCATION

E. CLINICAL FACULTY AND GOVERNANCE RIGHTS..... 402

F. HIERARCHIES WITHIN A CLINICAL PROGRAM .......... 403 IV.GOOD PRACTICES FOR HIRING, PROMOTION, AND RETENTION OF CLINICAL FACULTY

A. CLINICAL FACULTY UNDER A UNITARY TENURE-

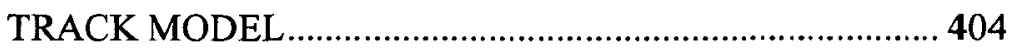

1. Hiring on a Unitary Tenure-Track ...................................405

2. Evaluation and Promotion on a Unitary Tenure-Track.... 405

3. Support for Clinical Faculty on a Unitary Tenure-Track.. 407

B. CLINICAL FACULTY UNDER A CLINICAL TENURETRACK MODEL .............................................................. 408

C. CLINICAL FACULTY UNDER A PRESUMPTIVELY RENEWABLE LONG-TERM CONTRACT MODEL .......... 410

D. CLINICAL FACULTY UNDER A SHORT-TERM CONTRACT MODEL .............................................................. 411

E. CLINICAL FELLOWSHIP PROGRAMS ...........................413

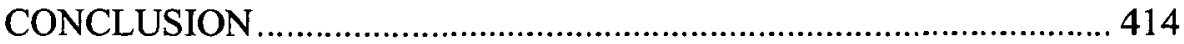




\section{INTRODUCTION}

The chair of the Association of American Law Schools (AALS) Section on Clinical Legal Education (Section) appointed us to the Task Force on the Status of Clinicians and the Legal Academy (Task Force) to examine who is teaching in clinical programs and using clinical methodologies in American law schools and to identify the most appropriate models for clinical appointments within the legal academy. ${ }^{1}$ The Task Force charges reflected two ongoing concerns: 1) the need to collect valid, reliable, and helpful data that would inform discussions on the breadth of clinical education in the legal academy and the status of clinical educators within the academy; and 2) the need to have a foundation for complex conversations on how American law schools should view and value their clinical teachers. The first primarily describes the present, while the second carries implications for the future.

The first task, the collection of data, was accomplished through the Center for the Study of Applied Legal Education (CSALE). In late 2007, CSALE sent a "master survey" to clinical program directors at the 188 American Bar Association (ABA) then fully-accredited law schools. Part of that master survey included a "staffing sub-survey" that was to designed to be answered by each person teaching in a clinic or field placement program at those 188 schools. One hundred forty-five schools responded to the master survey and 357 clinical educators from 70 law schools responded to the staffing sub-survey. ${ }^{2}$ The results of both surveys, available at www.CSALE.org, provide insight into various dimensions of clinical legal education, "including program design and structure, pedagogical techniques and practices, common program challenges, and the treatment of applied legal educators in the legal academy." " CSALE intends to update its data every three years, thus creating an ongoing longitudinal review of clinical legal education.

Data from the CSALE surveys appears throughout this Report, documenting the growing array of academic appointments for clinical faculty members. Importantly, this data informs this Report's discussion of the various models of clinical legal education and the place of clinical legal education and clinical faculty within the legal academy and its curriculum. Using CSALE data, this Report addresses the Task Force's second task: to

1. Charles Weisselberg, AALS Section on Clinical Legal Education, Task Force on Clinicians and the Academy 1 (Nov. 4, 2005) (on file with Task Force).

2. The results from both the master and staffing sub-surveys were determined to be representative of the target survey population as a whole using the chi-squared goodness of fit test. The staffing subsurvey, from which most of the data in this Report was taken, was more heavily populated by clinical educators from schools ranking in the top 100 of the 2007 U.S. News and World Report rankings.

3. Center for the Study of Applied Legal Education (CSALE), Report on the 2007-2008 Survey 1 (2008). 
identify and evaluate the most appropriate models for clinical appointments within the legal academy.

Our examination revealed that clinical faculty are employed under a myriad of appointment models, including tenure track. However, despite great strides in the growth of clinical legal education in the last 30 years, equality between clinical and non-clinical faculty remains elusive at most schools. ${ }^{4}$ Given that fact, this Report sets forth a path to equality. Drawing from the significance of events arising in the course of developing this Report, listening to the diverse voices of clinical legal educators at town hall meetings and through their completed CSALE surveys, reviewing the historical underpinnings of American legal education, and wrestling with several tension points, the Task Force arrived at four core principles and recommendations. The four core principles are:

(1) Clinical education is a foundational and essential component of legal education;

(2) The legal academy and profession benefit from full inclusion of clinical faculty on all matters affecting the mission, function, and direction of law schools;

(3) There is no justification for creating hierarchies between clinical and non-clinical faculty; and

(4) The standards for hiring, retention, and promotion of clinical faculty must recognize and value the responsibilities and methodologies of clinical teaching.

The Task Force concludes that these four core principles are best realized when full-time clinical faculty are predominantly placed on a unitary tenure track. To the extent that traditional tenure represents the legal academy's strongest expression of protection and support for its faculty, this Report urges law schools to extend this status to its full-time clinical faculty, or at minimum, to a predominant core of well-qualified full-time clinical faculty. Such clinical faculty also must have equal voting and governance rights, academic freedom, and in all other respects, be treated in like manner to other non-clinical faculty at similar career points in the legal academy. Furthermore, law schools must articulate standards for the hiring, promotion, and retention that reflect the unique responsibilities and methodologies of clinical legal education and clinical

4. References to "non-clinical faculty" in this Report denote faculty members who do not principally teach clinical courses and are tenured or on tenure track. This definitional choice reflects the fact that the availability of tenure is the norm for non-clinical faculty. The Task Force recognizes that other statuses exist for non-clinical faculty, but that the predominant status model is tenure. 
faculty. ${ }^{5}$ Exceptions to the tenure track requirement should be short-term contracts and clinical fellowship positions that are limited in number, duration, and purpose.

This Task Force's Report and Recommendations built on earlier efforts. In 2000, the president of the AALS convened a committee to consider a "Statement of Good Practices Regarding Clinical Faculty." Stopping short of "insist[ing] that [AALS] member schools predominantly staff their clinical programs with tenure track faculty members," the president charged the committee with finding the appropriate pathway to "convince law schools whose clinicians have irregular appointments to welcome them as full participants in the legal education enterprise." However, despite that committee's best efforts, it was unable to issue recommendations or conclusions. ${ }^{8}$ The committee's charge nonetheless remained an impetus for this Task Force, ${ }^{9}$ which has forwarded its final report to the Executive Committee of the AALS Section on Clinical Legal Education.

Prior to the convening this Task Force, the Section held a Town Hall Meeting at the May 2005 AALS Conference on Clinical Legal Education. Over 100 clinical teachers were present for a conversation "about our standing in the legal academy and whether, how, and what direction we should advance" vital issues of status and governance rights. ${ }^{10}$ Serving as a backdrop were then-pending changes to the ABA's interpretation of accreditation standard 405(c) which requires law schools to "afford to fulltime clinical faculty members a form of security of position reasonably similar to tenure, and non-compensatory perquisites reasonably similar to those provided other full-time faculty members." Emblematic of the array of opinions among clinical faculty about who they were and who they

5. To the extent this principle raises any perceived contradictions by urging equality while honoring differences between clinical and non-clinical faculty in their respective teaching, practice, service, and scholarship responsibilities, those tensions are addressed infra Part II.A.4.

6. Elliott S. Milstein, Academic Freedom, Law School Governance and Clinical Teachers, Ass'N OF AM. LAW SCHOOLS (AALS),Nov. 2000, at 1, available at http://www.aals.org/presidentsmessages/pmnov00.html.

7. Milstein, supra note 6.

8. Interview with Dean Aviam Soifer, Chair of the AALS Comm. on Good Practices Regarding Clinical Faculty, in Honolulu, Haw. (June 2004).

9. The appointment of this Task Force in 2005 followed discussions within the AALS Section on Clinical Education leadership to have the Section complete the work that the 2000 AALS committee began. The preamble of the charge to this Task Force referred to that earlier initiative, the lack of progress made by the AALS committee, and the need for the Section to resume and reenergize that call to action. Weisselberg, supra note 1 , at 1 .

10. Notes from the Town Hall Meeting of the AALS Section of Clinical Legal Education (May 2, 2005) (on file with Task Force).

11. A.B.A., SEC. OF Legal Educ. AND Admissions to the Bar, Standards and Rules of PROCEDURE FOR APPROVAL OF LAW SchOOLS, Std. 405(c) (2009) [hereinafter ABA Accreditation Standards]. 
should be were the reactions to the then-pending interpretations: at one end, welcoming the proposed interpretations as a source of greater protection and security, and on the other, construing the interpretations as a retreat from insistence on full tenure and a further stamp of harmful separation and inequality.

The Task Force held three additional Town Hall Meetings between May 2006 and May 2009 at the AALS annual conferences on clinical legal education. At the May 2006 meeting, it asked Section members to respond to two questions: (1) "Considering your particular faculty status, what are your most pressing challenges as they regard teaching, scholarship, service, and your voice within the academy?"; and (2) "If there are varying position, security, and participation in governance statuses for clinical teachers within your school, what concerns do they raise?"12 These questions again generated thoughtful discussion and the responses reflected a range of views on the desirability of tenure and other types of status for clinical faculty. In addition to the discussion at the meeting, the Task Force received over 100 written responses to these questions. ${ }^{13}$ This Report attempts to acknowledge all the voices sought and heard by the Task Force in its four years of work. While it cannot harmonize all the voices, it seeks to reflect an understanding of them.

In addition to these opportunities for input from clinical faculty, the Task Force met for three intensive weekend retreats for internal deliberation and debate about its recommendations in March 2007, October 2008, and April, 2009..$^{14}$ It is worth noting that the Task Force itself is comprised of members who were or are employed under different statuses in law schools from all regions of the country. Task Force members have been or are employed under short-term, long-term, fellowship, clinical tenure track, tenure track and tenure models; they have also occupied field placement program faculty and clinical program director positions. Consequently, its deliberations not only reflected the range and the passion of views expressed by members of the wider clinical community, but was informed by the diverse experiences of its authors.

The work of the Task Force has occurred against continuing controversy surrounding the role of the $\mathrm{ABA}$ in the regulation of law schools-especially its regulation of the terms and conditions of

12. On file with Task Force.

13. On file with Task Force.

14. In March 2007, the Task Force met at William S. Boyd School of Law, University of Nevada Las Vegas; in October 2008, at Seattle University School of Law; and in April 2009, at the University of Michigan Law School. The ability to meet face-to-face to deliberate the complex issues raised by questions of the role of clinical faculty in the academy was indispensible to reaching the eventual consensus represented by this Report. The Task Force is grateful to the law schools that supported this important aspect of its work with their hospitality, and to each Task Force member's law schools for supporting their individual efforts on this project. 
employment of clinical faculty. For years, the American Law Deans Association (ALDA) has campaigned to gain more decanal control over programmatic and employment status decisions, consistently opposing ABA accreditation standards and interpretations of those standards that have provided protections for the security of position for clinical faculty. In 2006, the ABA Council of the Section on Legal Education and Admission to the Bar appointed an Accreditation Policy Task Force to take a "fresh look at the accreditation process from a policy perspective." ${ }^{15}$ The Accreditation Task Force was unable to reach consensus on its "security of position" standards, including Standard 405(c), and referred the issue to the Council for further study and recommendation. ${ }^{16}$

In May 2007, in response to these ongoing deliberations by the ABA on the status of clinical faculty, the Task Force released an Interim Draft Statement of Fundamental Principles. ${ }^{17}$ The Draft Statement was intended to align the Task Force members in their vision and understanding of the Report's direction. It also conveyed to those engaged in deliberations over the status of clinical faculty the underlying principles that should guide any discussion. ${ }^{18}$ The May 2007 principles form the foundation for the core principles and recommendations in this Report. ${ }^{19}$

In 2008, an ABA Special Committee on Security of Position issued another report on possible changes to the ABA's security of position standards. The Committee's report found that "no law school can exist without faculty who has some security of position" and that "[a]cademic decision-making can only be undertaken by a committed, long-term faculty, dedicated to the institution's growth and development." ${ }^{20}$ The Special Committee further stated that nothing in the AAUP statements on academic freedom "says or implies that it might be permissible to discriminate against fields of study by allocating more academic freedom to some and less to others," noting that it was highly doubtful that any comprehensive curricular reform could occur without adequate provisions for security of position. ${ }^{21}$ The Special Committee, however, was unable to reach a consensus on whether the current ABA standards on terms and conditions of employment should be retained or changed. ${ }^{22}$ Even today, the issue of whether and how closely the ABA should regulate the security

15. A.B.A., SEC. ON Legal EDUC. AND ADMISSIONS TO THE BAR, REPORT OF THE ACCREDITATION TASK FORCE 1 (May 29, 2007).

16. A.B.A., supra note 15. at 22-23.

17. Task Force on Clinicians and the Academy, Draft Statement of Fundamental Principles (May 2007) (on file with Task Force).

18. Task Force, supra note 17.

19. Id.

20. A.B.A., REPORT OF THE SPECIAL COMMITTEE ON SECURITY OF POSITION 12 (May 5, 2008).

21. A.B.A., supra note 20 , at 6,12 .

22. Id. 
of position of clinical faculty and others in the legal academy is undergoing study. The ABA's Standards Review committee is currently reviewing the Accreditation Task Force's and Special Committee's reports and is expected to offer possible amendments to Standard 405 in 2010.

The work of the Task Force has also occurred against the backdrop of renewed attention and energy within the legal academy for reform of legal education. Although the deficiencies of relying on the traditional case method for preparing future lawyers for the practice of law have long been apparent, ${ }^{23}$ two publications in 2007 provided new analysis of these deficiencies and recommendations for reform.

First, the Carnegie Foundation for the Advancement of Teaching released its report on legal education, Educating Lawyers: Preparation for the Profession of Law, commonly known as the "Carnegie Report.,"24 Authored mainly by professional educators outside the legal academy, ${ }^{25}$ the Carnegie Report views legal education from the broader standpoint of professional education across multiple disciplines. The Carnegie Report is premised on the assessment that the heart of professional education is the development of expert professional judgment, or "the ability to act and think well in uncertain situations."26 All professional training, the Carnegie Report argues, involves three types of learning or "apprenticeships": cognitive; practical; and ethical. ${ }^{27}$ Consequently, to help law students develop expert professional judgment requires an interaction between formal knowledge and practice, in which students get the opportunity for intensive and theoretically-grounded analysis of their performance in practice. ${ }^{28}$ The Carnegie Report concludes that while the case method approach that dominates legal education is effective in developing a cognitive apprenticeship, it lacks connection to the practical and ethical aspects of lawyering, most notably the translation of legal knowledge into experience with clients and in the formation of professional identity. ${ }^{29}$

23. See generally Alfred Reed, Training for the Public Profession of the Law 276 (1921); A.B.A., REPORT AND RECOMMENDATIONS OF THE TASK FORCE ON LAWYER COMPETENCY: THE ROLE OF LAW SCHOOLS 26 (1979) [hereinafter THE CRAMTON REPORT]; A.B.A., SEC. ON LEGAL EDUC. AND ADMISSIONS TO THE BAR, LEGAL EdUCATION AND PROFESSIONAL DEVELOPMENT - AN EdUCATIONAL CONTINUUM, REPORT OF THE TASK FORCE ON LAW SCHOOLS AND THE PROFESSION 207-21 (1992) [ hereinafterTHE MACCRATE REPORT].

24. William M. SUllivan, et al., EduCATING Lawyers: PreParation For the Profession of LAW (2007) [hereinafter Camegie Report].

25. Although she was the Carnegie Report's principal investigator, Judith Welch Wegner (University of North Carolina) was the only law professor on the five-member team that researched and wrote the Report.

26. Carnegie Report, supra note 24 , at 9.

27. Id. at 27-28.

28. Id. at 10 .

29. Id. at 57-58. 
Second, the Best Practices for Legal Education report ("Best Practices Report") drew on educational theory to recommend that law schools set educational goals framed in terms of desired learning outcomes and employ context-based education that integrates theory, doctrine, and skills throughout the law school curriculum. ${ }^{30}$ As of 2009 , over fifty U.S. law schools have adopted, or are in the process of grappling with, curriculum reform guided in part by the Carnegie and Best Practices Reports. ${ }^{31}$ Many of those reforms focus on ensuring that throughout the curriculum students are being taught the core principles involving the "apprenticeship of practice."

This Report goes beyond an articulation of core principles and recommendations regarding clinical legal education and clinical faculty status. This Report also aims to help law schools make informed choices about their clinical programs during a time that portends both great promise for curricular reform in legal education and great risk for loss of security of position for clinical faculty in the academy. Although the Task Force has concluded that only one status - tenure for full-time clinical faculty-is ultimately appropriate, it recognizes that moving law schools toward its recommendations may be gradual for even the best-intentioned institutions, and that schools may need to employ a hybrid of models to staff their clinical programs as interim measures. This Report is also written to assist those law schools by elucidating for all status models good practices consistent with the four principles that underlie the recommendations. To that end, this Report proposes good practices for five status models commonly used for clinical faculty at American law schools: unitary tenure track, clinical tenure track, long-term contract, short-term contract, and clinical fellowships. Although numerous titles and terms suggest that more than five models exist, the Task Force selected these models because they approximate the range of choices considered or used at almost every American law school.

Part I of this Report presents an overview of the nature of clinical legal education, the regulation of clinical faculty status, and a description of the five status models that have formed the basis for our analysis. Part II describes the recommendations in more detail. It first explains the four core principles on which the recommendations lie and then further develops our recommendations in favor of a unitary tenure model for clinical faculty over clinical tenure and long-term contract models, while recognizing a continuing but limited role for short-term contract and clinical fellowship positions within a program staffed primarily by tenured

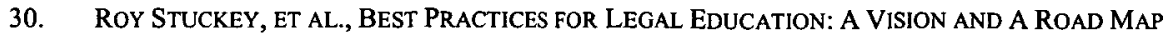
(2007) [hereinafter Best Practices Report].

31. Data on file with Task Force. 
and tenure-track clinical faculty. Part III discusses and responds to some of the likely "tension points" raised by our recommendation for a unitary tenure model. Part IV concludes with more detailed descriptions of how all five models ought to be implemented consistent with the four core principles and recommendations.

\section{CLINICAL FACULTY IN THE LEGAL ACADEMY}

This Section sets out the building blocks for the Task Force's core principles and recommendations, providing a description of the enterprise of clinical legal education, the current standards and interpretations that regulate the status of clinical faculty in the academy, and a snapshot of the status of clinical faculty in American law schools today. Part A describes the unique teaching, service, and scholarship attributes of clinical legal education, explaining the basic structure and method of clinical teaching, the deeply rooted social justice mission of clinical legal education, and scholarship by clinical faculty. Part B describes the development of ABA regulation of full-time clinical faculty status through its accreditation standards and provides an overview of the governing regulations today. Using the CSALE data, Part $\mathrm{C}$ describes the five predominant status models of clinical faculty and gives an overview of what the CSALE data reveals about the governance rights, teaching responsibilities, scholarship requirements, and support for scholarship in each of the various models.

\section{A. THE NATURE OF CLINICAL LEGAL EDUCATION}

\section{Clinical Teaching}

Clinical legal education is steeped in what the Carnegie and Best Practices Reports describe as "context-based education." course materials for clinical and field placement instruction are cases, specifically law students' experiences representing actual clients. Client representation occurs within a host of legal contexts: civil and criminal litigation; business, organizational, or individual transactional needs; alternative dispute resolution; and community development and administrative advocacy. ${ }^{33}$ Cases arising from these contexts are used as

\footnotetext{
32. Camegie Report, supra note 24, at 95; Best Practices Report, supra note 30, at 141.

33. Field placement programs (i.e., externships) vary in design but generally utilize a distinct mode of instruction. In field placement programs students work for academic credit in legal settings outside the law school under the supervision of practicing attorneys and also attend related seminar classes taught at the law school by a member of the faculty. Kelly S. Terry, Externships: A Signature Pedagogy for the Apprenticeship of Professional Identity and Purpose, 59 J. LEGAL EDUC. 240, 243 (2009); see also ABA Accreditation Standards, Std. 305 (setting requirements for study outside the classroom, including field placement programs).
} 
vehicles for developing both the practical skills and professional judgment necessary to legal practice. In both live client and field placement programs, students are typically placed in the role of lawyer, representing clients under circumstances that are complex, undefined, and ever-shifting. Law school clinics and field placement programs vary widely in subject matter, and even within a program, students may experience a different mix of challenges depending on what arises in their cases. Despite these variations, clinical legal education uniformly presents students with the opportunity to experience the complexity of legal issues as they arise in the lives and situations of real clients; the complexity and indeterminacy of facts as they are developed and analyzed in the course of legal representation; and the opportunity to engage in a lawyer-client relationship in which they must employ interpersonal interviewing and counseling skills to ascertain clients' goals and to integrate law, procedure, legal ethics, and policy in pursuing those goals.

Clinical pedagogy may be best described as a methodology of "Prepare-Perform-Reflect." Students typically take the lead in "performing" the essential tasks of lawyering: client interviewing and counseling; factual investigation; negotiation; mediation; oral advocacy; document drafting (e.g., letters, memoranda, position statements, court pleadings); and resolving ethical dilemmas. Clinical faculty provide the supervision necessary to support the students' preparation for events such as client meetings, witness interviews, hearings, and court, mediation or negotiation appearances, and they structure the students' critical reflection following those events. Clinic faculty guide students to engage in thoughtful planning, give detailed feedback on student performance, and engage students in studied reflection that ties their casework to larger issues in related areas of law, social justice, and lawyering. Because students in clinical programs most often represent poor, marginalized clients, clinic courses offer unparalleled opportunities for students to critically reflect on the fairness and justice of laws and the operation of legal systems in the lives of clients.

Although law clinics vary widely in their design, virtually all law clinic courses utilize three basic modes of instruction: 1) seminar discussion; 2) case rounds; and 3) one-on-one supervision. ${ }^{34}$ In live client clinic seminars, students learn the basic knowledge necessary to their casework the doctrinal, legal, procedural, ethical, social, political, or economic substance that they will be required to apply in context. The seminars also

34. For a discussion of case rounds in live client clinics, see Susan Bryant \& Elliot S. Milstein, Rounds: A "Signature Pedagogy" for Clinical Education?, 14 CliniCAL L. REV. 195, 197 (2007). Most field placement programs incorporate some discussion of legal work, but the content varies depending on how the program has defined the clinical faculty member's relationship to the field placements and the placements' legal work. 
serve as an opportunity for instruction in professional skills they will likely be called upon to perform, such as client interviewing and counseling, negotiation, or trial advocacy. In field placement programs, seminars may address similar topics or may address more general topics designed to develop students' professional identities. In both contexts, the seminar component also may be used to learn ethical rules related to the students' practice or to read and discuss articles that raise larger policy, social justice, or lawyering issues. The myriad concepts which underlie professional skills and values learning have their own substantive and extensive pedagogical histories. However, because no general textbook can capture the depth and specificity of information needed to instruct students in their casework, clinic faculty typically develop individualized course materials that cover a range of subjects. Clinic course materials often compile local substantive and procedural law, excerpt lawyering skills or other practice materials, and include readings that analyze or critique law, legal systems, or the lawyering process. ${ }^{35}$

Case rounds are a special type of seminar class or group session designed to generate student discussion of practice, policy, or ethical issues that arise in their cases, to help students draw general lessons about law or lawyering from their specific cases, and to build camaraderie by learning about each others' cases and from each other ${ }^{36}$ In live-client clinics, students may be assigned to present a particular aspect of one of their cases for case round discussion. Other times, professors may identify a recurring issue for discussion and draw out perspectives on it from the work of students in different cases. In case rounds, students may discuss themes or policy issues that run through cases, wrestle with ethical issues that have arisen in a particular case, brainstorm strategy, provide peer feedback on student work, or help other clinic students prepare for an upcoming event in a case by mooting legal arguments, role-playing client interviews, or practicing witness examinations. For the clinical faculty member, case rounds demand more than a passing understanding of student cases. Case rounds demand thoughtful preparation and distillation of factual, legal, ethical, or procedural themes, and careful development of classroom methods through which students may illuminate those themes.

In field placement programs, the content of case round discussions may vary due to confidentiality issues, ${ }^{37}$ but their function is similar: facilitating

35. Clinical faculty teaching in a field placement program coordinate all field placements, train and supervise field supervisors to ensure the pedagogical soundness of the placements, teach the seminars, and guide the externs' reflections.

36. See generally, Bryant \& Milstein, supra note 34 .

37. See, e.g., Alexis Anderson, Arlene Kanter, and Cindy Clane, Ethics in Externships: Confidentiality, Conflicts, and Competence Issues in the Field and In the Classroom, 10 CLINICAL L. REV. 473 (discussing an externship model where the clinical faculty member has no responsibility for the students' cases and therefore precluded form knowing confidential client information); Margaret 
the students' learning from their experiences. For those students, the "combination of work experiences in actual practice settings and guided reflection on those practice experiences in the seminar provides students with an ideal opportunity to explore the moral, ethical, and professional dilemmas that lawyers regularly encounter." ${ }^{38}$ As in live client clinic courses, students learn the fundamental values of the profession, and observe and adopt the professional norms that will guide their careers while getting hands-on training and experience with professional skills. ${ }^{39}$

Perhaps the most central and important clinical teaching occurs in oneon-one supervision sessions, in which clinical teachers, faculty and field placement supervisors meet with individual students or student teams to discuss the progress on their cases, provide feedback, reflect on events that have occurred in the cases, and plan for next steps. ${ }^{40}$ Broadly speaking, supervision sessions concern themselves with four goals: deepening students' knowledge of relevant laws, rules, regulations or procedures necessary to the next steps in a case; examining existing and emerging facts that impact the client's goals or case strategy; identifying and preparing students for upcoming tasks; and fostering the students' self-knowledge through guided reflection (through dialogue or journals) upon professional performance, professional role, and the manifold relationships between the student, client, mentor, and others involved in the representation. Most clinical faculty formalize these sessions into their weekly schedules and prepare teaching goals for them. Thus, in every sense, the nature of clinical teaching connects the cognitive, practical, and ethical aspects of lawyering, and provides students opportunities to apply their knowledge while meeting clients' needs and to develop their professional identities.

As a result of its unique pedagogical structure, clinical teaching is not only intellectually challenging, but time-intensive and unpredictable. It takes patience and persistence to develop in a student the legal, procedural, strategic, and professional skills required to perform the tasks of a lawyer in a real case. The additional reflective component of clinical pedagogy requires teachers to constantly step back from the demands of the casework and strategize how to structure discussions with individual students and among groups of students to maximize student learning in both individual supervision settings and case round settings. The work of clinical teaching

Martin Barry, Jon Dubin, and Peter Joy, Clinical Education for the Millennium: The Third Wave, 7 ClINICAL L. REV. 1 (2000) (identifying a "hybrid externship model" where clinical faculty have joint responsibility, with the field supervisors, for the students' legal work).

38. Terry, supra note 33 , at 243.

39. Id.

40. See Ann Shalleck, Clinical Contexts: Theory and Practice in Law and Supervision, 21 N.Y.U. REV. L. \& SoC. CHANGE 109 (1993-1994); Margaret Martin Barry, Clinical Supervision: Walking that Fine Line, 2 CLINICAL L. REV. 137 (1995). 
is aided by a high level of student engagement in representing real clients whose legal affairs depend on the students' mastery of the relevant law, procedure, facts, and necessary lawyering skills.

However, as with the work of all lawyering, clinical teaching lacks predictability, nor can it easily be cabined within a planned timeframe. The flexible, responsive, and individualized nature of clinical teaching and client representation deprive clinical faculty of the "economies of repetition" that classroom teachers enjoy. Although the demands of traditional classroom teaching are also quite intensive in early years of teaching, the time required to prepare a class diminishes as the class is repeatedly taught. This is not the case with clinical teaching, where required substantive and procedural knowledge is driven by emergent case facts. Thus, the relevant law and procedure may vary from case to case, even within a single clinical course. As a result, clinical teaching is timeintensive, and may even expand its time demands as clinical faculty become more deeply engaged in community and policy initiatives that reach beyond the work of their students.

\section{The Social Justice Mission of Clinical Legal Education}

The history of American clinical legal education has imbued the current clinical culture with a bent toward social justice and has attracted faculty whose practice backgrounds commonly reflect a commitment to public service, especially to society's most vulnerable populations. ${ }^{41}$ Law school clinical programs reflect this "social justice mission" in various ways. Some emphasize law reform - either through test case litigation or legislative advocacy - with the goals of exposing students to law as a tool for social change. Another manifestation of clinical legal education's social justice mission is a focus on community or collaborative lawyering, which emphasizes understanding the social, political, and economic dynamic in a local community, developing non-traditional lawyering skills, and exploring an alternative lawyer-client relationship that rejects traditional notions of power. Still other clinics may incorporate community education into their work, involving students in researching and preparing training materials, conducting training sessions to assist non-lawyers to better advocate for themselves, or assisting social service, education, mental health, medical, and other professionals in understanding legal principles. In doing so, the social justice mission of clinical programs also serves as a vehicle for another vital aspect of professional identity

41. See generally, Jon Dubin, Clinical Design for Social Justice Imperatives, 51 SMU L. REV. 1461 (1998); Jane H. Aiken, Provocateurs for Justice, 7 ClINICAL L. REV. 287 (2001); Stephen Wizner, Beyond Skills Training, 7 CLINICAL L. REV. 327 (2001). 
formation, that of shaping students as leaders in the communities they will come to serve.

A clinical program with a strong social justice mission will typically focus on providing legal representation to clients who are excluded or otherwise marginalized in the legal process, work closely with the local community to identify areas in which legal services are deficient, and attempt to tie client representation to larger law reform or social reform agendas. ${ }^{42}$ Clinical programs often incorporate a social justice mission by exposing students to a wide range of lawyering techniques to advance the interests of a specialized group of clients. For example, a clinic focusing on domestic violence might represent clients in securing protective orders, provide training on the law to the police and social services community, lobby for enhanced legislation to protect survivors of domestic violence, and implement a "court watch program" to evaluate the judiciary's treatment of litigants in domestic violence cases. Such a practice exposes students to various lawyering skills and strategies that enhance advocacy for a select population.

As a result of the social justice mission of clinical legal education, the service responsibilities of clinical faculty in the community are often higher and more intensive than the service responsibilities of a typical doctrinal classroom teacher. The typical load of faculty service work is augmented for clinical faculty by the substantial time they devote to community engagement, including developing and maintaining good relationships with judges, members of the bar, and local legal services and advocacy groups. Conducting or coordinating continuing legal education seminars, participating on bar committees, and serving on boards are just a few examples of service in furtherance of social justice and law school mission. For those teaching in field placement programs, cultivating and maintaining these relationships is even more essential. This engagement benefits law schools, which often rely on clinical faculty to interface with and actively engage the surrounding community. To be sure, many, if not most, schools actively promote their clinical programs and faculty - on school websites, in newsletters, in speaking engagements-as emblematic of the institution's commitment to the surrounding community and to social justice. Community engagement also benefits the quality of clinical legal education by keeping clinical teachers conversant on emerging issues in their fields of practice and opening doors to new learning opportunities for students.

42. Dubin, supra note 41; see also Antoinette Sedillo-Lopez, Learning Through Service in a Clinical Setting: The Effect of Specialization on Social Justice and Skills Training, 7 CLINICAL L. REV. 307 (2001). 
The social justice mission of clinics also requires institutional support to thrive. To assess and respond to community needs, clinical faculty need the longevity and job stability to engage deeply over time in the local community. Moreover, the representation of marginalized clients often places clinical faculty at odds with established institutional powers. As a result, a number of clinical programs have been attacked by legislators, alumni, business interests, and even judges themselves, over their choice of clients or handling of legal matters, and clinical faculty may need institutional protection from political interference from groups hostile to clinical program cases and social justice goals. ${ }^{43}$

\section{Scholarship by Clinical Faculty}

Clinical faculty contribute to scholarly discourse in at least three ways: (1) by producing law review articles and books about law, policy, and procedure from a unique and valuable perspective embedded in practice; (2) by producing uniquely clinical scholarship that deepens the understanding of clinical program design and pedagogy; and (3) by producing educational, legal, and policy reform materials that entail broader research and policy analysis beyond what law practice typically provides. ${ }^{44}$ As clinical faculty have become more established within the academy, their scholarly work in all of these areas has been recognized through both traditional tenure and alternative promotion and retention standards.

Straddling the line between practice and academia, clinical faculty are well-positioned to identify legal issues worthy of extensive critical analysis in traditional scholarship, and when they engage in traditional legal scholarship, clinical faculty bring a different and valuable perspective to the legal academy. Most traditional doctrinal legal scholarship accesses law through published opinions in appellate cases. By contrast, clinical faculty see legal doctrine, theory, and processes from the "bottom up." The law to which they are regularly exposed in clinical teaching is the law as it is implemented by low-level legal decision makers like trial judges, magistrates, administrative law judges, court clerks, local officials, and police officers. Moreover, it is the law that often touches the lives of the poor and otherwise disempowered persons and communities served by

43. See Robert R. Kuehn \& Peter A. Joy, Lawyering in the Academy: The Intersection of Academic Freedom and Professional Responsibility, 59 J. LEGAL EDUC. 97,98 (2009).

44. The Clinical Law Review periodically publishes an annotated bibliography of scholarly works by clinical faculty on clinical topics. The list is impressive in the quantity of works and breadth of topics addressed. The most recent list, published in 2005, contains over a thousand entries. J.P. Ogilvy with Karen Czapanskiy, Clinical Legal Education: An Annotated Bibliography (3d ed.) ClinICAL L. REV. (Special Issue No. 2) (2005). 
clinical programs. Because clinical faculty are also teaching through methods of critical reflection on practice, clinical teaching provides the opportunity to translate clinical faculty perspectives on practice into scholarly discourse in interesting and important ways.

Some areas of traditional legal scholarship have natural connections to the embedded "bottom up" and critical perspectives of clinical faculty. For example, there is a natural connection between the perspective of clinical faculty on law and the body of "law and society" scholarship that uses empirical methods to investigate legal processes below the radar of appellate case study. Moreover, the focus clinical faculty bring to the problems and perspectives of poor and disempowered people and communities has common ground with critical or narrative-based scholarship, which often uses the experiences of marginalized persons and communities to challenge the ideological assumptions on which law is based. Even when clinical faculty write more traditional doctrinal scholarship, as those in tenure-track positions increasingly do, they are well-positioned to investigate the ways doctrine will or could be put into practical effect, or the places where different kinds of legal doctrine intersect in the lives of persons affected by the law.

In addition, the past 10-15 years have seen the growth of a unique body of "clinical scholarship" which analyzes and debates the merits of various approaches to clinical pedagogy and clinical program design. Unlike doctrinal classes, which have a well-developed stable of casebooks in most subject areas, the teaching materials used in clinical education vary widely. Thorough and well-developed scholarship that focuses on the pedagogical challenges and choices of clinical teaching makes an important contribution to the development of clinical pedagogy and to deeper understandings of law and the legal profession. Since the establishment of the Clinical Law Review in 1994, clinical scholarship has become even more established and influential in advancing a national dialogue about the goals and methods of clinical legal education.

Finally, clinical faculty have been encouraged through expansive or alternative promotion and retention standards to contribute to the formation of law and policy through the production of amici briefs, training manuals, policy papers, and other written materials that require both broad research and deep analysis. Because clinical faculty stand with one foot in practice and the other in the academy, they are ideally located to understand, research, and analyze issues of broader law and policy that affect the clients they serve. Although such law and policy reform work is not published in law review journals, it often requires a similar investment of time and intellectual energy, with an eye toward providing guidance and change on specific pending local or national issues. 


\section{B. ABA REGULATION OF CLINICAL FACULTY STATUS}

As clinical education has become more established within the law school curriculum, the ABA has used its law school accreditation standards to push law schools to integrate clinical faculty into the life and governance responsibilities of law school faculties. ${ }^{45}$ Prior to the $1980 \mathrm{~s}$, the ABA Standards for law school accreditation included a general standard on the competence of all members of the faculty, but nothing specifically addressed clinical faculty. In 1984, troubled by the unequal treatment of clinical faculty and its negative effect on advancing clinical legal education, the ABA adopted Standard 405(e), which provided, in part, that a law school "should afford to full-time faculty members whose primary responsibilities are in its professional skills programs a form of security of position reasonably similar to tenure and perquisites reasonably similar to those provided other full-time faculty members. ${ }^{.46}$ The ABA interpretations of Standard 405(e) explained that a form of security of position reasonably similar to tenure includes a separate tenure track or a renewable long-term contract, but conceded that the new standard did not preclude a limited number of fixed, short-term appointments in a program predominantly staffed by full-time faculty or in an experimental program of limited duration. In 1988, after hearing reports that many law school were still denying clinical faculty opportunities to participate in law school governance, the ABA adopted an interpretation to Standard 405(e) stating that law schools "should" afford full-time professional skills faculty "an opportunity to participate in law school governance" in a manner "reasonably similar to other full-time faculty members."

In 1996, the ABA rejected a call to deregulate the status of clinical faculty members and instead strengthened the protection of their status. After determining that the language of Standard 405(e), which provided that professional skills faculty "should" have a role in law school governance, was not having its desired effect, the ABA made the standard mandatory by inserting the term "shall." The current standard now codified as Standard 405(c) states:

A law school shall afford to full-time clinical faculty members a form of security of position reasonably similar to tenure, and noncompensatory perquisites reasonably similar to those provided other full-time faculty members. A law school may require these faculty members to meet standards and obligations reasonably similar to those required of other full-time faculty members.

45. For a full history of ABA Standards addressing clinical faculty, see Peter A. Joy \& Robert R. Kuehn, The Evolution of ABA Standards for Clinical Faculty, 75 TENN. L. REV. 183 (2008).

46. A.B.A. ACCREDITATION STANDARDS, Std. 405(c). 
However, this Standard does not preclude a limited number of fixed, short-term appointments in a clinical program predominantly staffed by full-time faculty members, or in an experimental program of limited duration. ${ }^{47}$

Interpretation 405-6 explains that a form of security of position reasonably similar to tenure "includes a separate tenure track or a program of renewable long-term contracts." Long-term contracts are defined to mean "at least a five-year contract that is presumptively renewable or other arrangement sufficient to ensure academic freedom." Under either approach - after clinical tenure is granted or a long-term contract is provided - the clinical faculty member may be terminated only for "good cause, including termination or material modification of the entire clinical program." Interpretation 405-8 explains that law schools "shall afford to full-time clinical faculty members participation in faculty meetings, committees, and other aspects of law school governance in a manner reasonably similar to other full-time faculty members." Interpretation 405 7 clarifies that law schools are required to "develop criteria for retention, promotion, and security of employment of full-time clinical faculty," and explains that "competence in the areas of teaching and scholarly research and writing should be judged in terms of the responsibilities of clinical faculty."

In the shadow of shifting $\mathrm{ABA}$ regulations, law schools have developed a variety of types of employment status that control the job security, governance rights, and promotion criteria for clinical faculty. Clinical faculty can be found in positions that range from fully integrated faculty status with governance rights on all issues, to one-year, nonrenewable contract positions with virtually no participation in law school governance. The next section summarizes the five most identifiable status models that the Task Force has used as a basis for comparing and evaluating the status of clinical faculty in the legal academy.

\section{FIVE MODELS OF CLINICAL FACULTY STATUS}

There are currently over 1400 clinical faculty teaching at American law schools in law clinic courses and field placement programs. ${ }^{48}$ Clinical faculty members hold a wide range of statuses among those law schools. ${ }^{49}$

47. A.B.A. ACCREDITATION STANDARDS, Std. 405(c).

48. Kuehn \& Joy, supra note 43, at 98 (citing 2007 statistics).

49. It is worth noting that schools with the twenty highest-ranked clinical programs in 2009, according to U.S. News and World Report, significantly rely on some form of tenure or presumptively renewable long-term contracts for their clinical faculty appointments. Among the top ten clinical programs, $60 \%$ predominantly employ full-time clinical faculty under traditional tenure lines. 
Even within a single law school, status varies. Presently, most schools employ clinical faculty on different tracks, with some law schools reserving tenured positions, if they exist, for clinical program directors. ${ }^{50}$ Conversely, most schools employ non-tenure track clinical teachers to staff at least part of their clinical faculty. Each track, or what we call status model, is discussed below. Along with the description of each status model, this Report examines its teaching, scholarship, governance, and service characteristics. This range of employment models reflects both the different ways law schools have responded to the emergence of clinical legal education and the shifting regulatory standards that have evolved through the ABA accreditation process.

For purposes of this Report's analysis of the status of clinical faculty, we have divided clinical positions into five primary status models: unitary tenure track; clinical tenure track; long-term contract; short-term contract; and clinic fellowships. Although numerous titles and terms suggest that more than five models exist, the Task Force selected five models that approximate the range of choices considered or used at almost every law school. This section sets forth a short description of each model and an analysis of the data from CSALE regarding the rights and responsibilities that currently attend each model.

\section{Unitary Tenure-Track}

For the purpose of this Report, "tenure" refers to the "arrangement whereby faculty members, after successful completion of a period of probationary service,can bedismissed only for adequate cause or other possible circumstances and only after a hearing before a faculty committee." ${ }^{.51}$ Clinical faculty members employed on a traditional or "unitary" tenure-track model gain tenure through the same process and enjoy the same security of position and governance rights as tenured nonclinical faculty members. They also enjoy the same academic freedom in their research, teaching, and (presumably, by extension) practice. Unlike clinical tenure, which is defined programmatically and applies only to clinical faculty, the unitary tenure-track model integrates clinical faculty fully into law school faculties.

Extending out to the twenty top-ranked programs, this percentage drops slightly to $57 \%$ for traditional tenure and tenure track. Among the top ten clinical programs, $20 \%$ predominantly employ clinical tenure appointments for their clinical faculty, while $20 \%$ predominantly rely on long-term contract appointments. None of the top ten clinical programs predominantly use short-term contracts.

50. Kuehn \& Joy, supra note 43 at 98.

51. AAUP, Issues in Higher Education - Tenure, http://www.aaup.org/AAUP/issues/tenure. 
Based on the 2007 CSALE survey, tenured or tenure-track clinical faculty members comprise $27 \%$ of all full-time clinical faculty nationally, ${ }^{52}$ and $48 \%$ of all $\mathrm{ABA}$ accredited law schools employ at least one tenured or tenure-track clinical faculty. Clinical faculty who report being employed on the tenure and tenure track have governance rights identical to other tenured and tenure-track faculty members: $100 \%$ of tenured clinical faculty reported voting on all matters of faculty governance.

The unitary tenure-track model universally includes a requirement to pursue a scholarly agenda. Eighty-three percent of clinical faculty on a unitary tenure-track model report that retention and promotion standards require scholarly publication of the same type and in the same number as any other tenure-track faculty members. However, some law schools recognize that the type, subject matter, number, and length of scholarship produced by clinical faculty may differ from traditional classroom faculty and have developed promotion and retention policies to reflect those differences. For example, some schools require the same kind of writing, topics, and journal placement, but reduce the number of required pieces to account for the unique demands on a clinical faculty member's time. Tenure standards at other schools recognize other differences, such as assigning more weight to teaching or crediting other types of writings, such as training manuals and bar journal articles aimed at the practitioners, significant advocacy pieces on behalf of clients, or "white papers" that advance sophisticated concepts or policy concerns.

Support for scholarship among clinical faculty on a unitary tenure track is consistent with the support provided to non-clinical faculty, but does not always address the unique needs of clinical faculty for support. For example, although $100 \%$ of tenured and tenure-track clinical faculty reported that they received financial support for scholarship, not all enjoyed summer coverage of cases. Among clinical faculty on the unitary tenure track, only $39 \%$ report getting funding to employ an attorney to cover cases over the summer. Still, these percentages exceed those for attorney assistance in other job status categories.

\section{Clinical Tenure-Track}

The clinical tenure-track model draws on the example of other professional schools - for example, medical, nursing, and dental schools that provide academic appointments with programmatic tenure for individuals whose primary responsibilities focus on teaching professional skills. Unlike the unitary tenure-track model, which for the most part

52. The data included in this Section of the Report is drawn from the 2007 CSALE survey and is on file with the Task Force. 
extends identical status, security, governance, and financial benefits to clinical and non-clinical faculty members, the clinical tenure-track model creates a separate tenure system for clinical faculty. In doing so, it demarcates clinical faculty from their non-clinical colleagues in the process and standards for gaining clinical tenure.

Approximately $13 \%$ of clinical faculty are employed under a clinical tenure-track model. Governance rights vary among schools with clinical tenure systems. However, the majority limit governance rights of clinicaltenured faculty compared to their non-clinical colleagues. For clinicaltenured faculty, $63 \%$ are permitted to vote on all matters of faculty governance; $30 \%$ are permitted to vote on all matters except the hiring and promotion of non-clinical faculty; $4 \%$ are permitted to vote on administrative matters only; and $4 \%$ are not permitted a vote on any matter, but are permitted to attend faculty meetings. For clinical tenure-track faculty, governance participation drops further: $20 \%$ are permitted to vote on all matters; $70 \%$ are permitted to vote on all matters except the hiring and promotion of non-clinical faculty; and $10 \%$ are not permitted to vote on any matter but are permitted to attend faculty meetings. In addition, the participation rights of clinical tenure-track faculty in law school committees are typically more limited than clinical faculty on a traditional tenure track.

A factor that further demarcates the clinical tenure-track model from the unitary tenure model is its differing standards for hiring, promotion, and retention. Ninety-seven percent of clinical tenured and tenure-track respondents in the CSALE survey reported differences in the written standards for their retention and promotion as compared to other members of the tenure-track faculty. The prevalence of scholarship as a requirement in these standards is significantly less than for those on unitary tenure track. Only $47 \%$ of clinical faculty on clinical tenure track report scholarship as a job requirement. Among this $47 \%, 90 \%$ received financial support for research assistance, as opposed to $100 \%$ for those on unitary tenure track. Support for summer case coverage also drops in this group: only $15 \%$ report receiving funding to employ an attorney to cover cases over the summer as opposed to $39 \%$ among clinical faculty on unitary tenure track.

Among clinical faculty on clinical tenure track where scholarship was considered in hiring and promotion decisions, the majority of the differences turned on the acceptance of works that depart from traditional law review articles but carry an equivalent level of intellectual inquiry and rigor. ${ }^{53}$ In addition to differences in the forms, topics, and placement of scholarship, schools using a clinical tenure track may adjust the quantity of

53. For example, $83 \%$ reported greater acceptance of "applied scholarship" and $57 \%$ reported greater acceptance of briefs and similar works. 
writings to satisfy promotion, tenure, and post-tenure review standards. Seventy-eight percent of clinical faculty on clinical tenure track working under different standards than non-clinical faculty reported that the number of publications they were required to produce for tenure was lower than the number required of their tenure-track colleagues. For example, one school recognized that its traditional scholarship requirement of a major article every other year and a minor article in alternate years was not viable for its clinical tenure-track faculty in light of their clinical workload. Instead, its clinical faculty must produce a "significant piece of scholarship" and a "less scholarly piece" every six years. In all cases, scholarship standards in clinical tenure-track programs are designed to include the specific expertise, interests, and activities of clinical faculty.

Many programs with a clinical tenure-track emphasize excellence in teaching as the hallmark for promotion and tenure and some base retention and promotion decisions solely on demonstrated excellence in teaching. Seventy-four percent of clinical faculty on a clinical tenure track reported that their promotion and retention standards place a greater emphasis on the quality of their teaching, compared to their unitary tenure-track colleagues. The promotion and tenure standards at such schools articulate standards for judging excellence in teaching that are grounded specifically in clinical teaching methodology. What sets them apart is the articulation of clinicspecific teaching goals, methods, and tasks.

Service expectations can differ and possibly be higher for clinical faculty under a clinical tenure-track system than for those under the traditional tenure-track system. Importantly, service expectations of faculty under a clinical tenure system typically encompass state and local bar activities, participation in continuing professional education, and participation in litigation or other activities that raise important questions of public policy. In fact, $78 \%$ of law faculty in a clinical tenure-track model reported that such community involvement counted toward promotion and retention.

\section{Long-Term Contract}

For purposes of this Report, a "long-term contract" is an employment contract of five or more years in duration and presumptively renewable. In some institutions, the long-term contract is conditioned on the faculty member successfully completing one or more "probationary" periods lasting one to three years. Clinical faculty on contracts of five or more years represent just over $21 \%$ of full-time clinical faculty. Ninety-five percent of clinical faculty on contracts of five years or longer have security of position in the form of a presumption of renewal. The CSALE statistics 
that follow address only this $95 \%$ whose contracts carry the presumption of renewal.

For these long-term contract clinical faculty, governance rights are typically less than the rights accorded tenured faculty. Only $15 \%$ of these clinical faculty have voting rights on all matters of faculty governance. Sixty-nine percent are permitted to vote on all matters except the hiring and promotion of doctrinal faculty. Five percent are permitted to vote on administrative matters only and $11 \%$ are not permitted to vote on anything, although they can attend faculty meetings. Seventy percent of clinical faculty on long-term contracts are prohibited from participating on committees that address the hiring and promotion of faculty who teach doctrinal courses. Moreover, $20 \%$ are barred from committees focusing on the hiring and promotion of other clinical faculty.

Scholarship requirements among this cohort differ significantly from the unitary tenure track and clinical tenure-track models. Only $21 \%$ of those on presumptively renewable contracts of five or more years in length report that scholarship is a job requirement. However, for those who were required to produce scholarship, $91 \%$ receive some form of financial support, but just $10 \%$ receive relief from teaching to support scholarly work. Only $2 \%$ of the cohort who are required to produce scholarship reported the receipt of funding to employ an attorney to cover cases over the summer to facilitate the pursuit of scholarly interests. This number stands in stark contrast to the $15 \%$ of clinical faculty on clinical tenure track and the $39 \%$ on unitary tenure track who report receiving such funding.

\section{Short-Term Contract}

This Report defines a "short-term contract" as an appointment that is not presumptively renewable and is less than five years in duration. Fifteen percent of all clinical faculty report being employed on short-term contracts so defined. ${ }^{54}$ When including clinical faculty employed on all variations of short-term contracts without the presumption of renewal, including adjuncts or staff attorneys, ${ }^{55}$ this percentage increases to $20 \%$ of all clinical

54. There is a small group of clinical faculty who report contracts of less than 5 years in duration but with a presumption of renewal. This group constitutes just $8 \%$ of all full-time clinical faculty. The presumption we make with this group - the question was not directly posed in the CSALE Survey - is that these clinical faculty are working in probationary periods akin to pre-tenure non-clinical faculty and pre-tenure clinical tenure-track faculty. Based on this presumption, we have excluded them from the analysis in this section which focuses on clinical faculty working without the job security a contractual presumption of renewal brings.

55. As their title suggests, these attomeys staff a clinic and assist day-to-day lawyering and case supervision functions. They also may have partial or sole responsibility for teaching. Unlike adjuncts, their primary practice is in the clinical program. 
faculty. Reliance upon short-term contract clinical faculty is widespread: over $56 \%$ of all ABA-approved law schools have at least one clinical educator employed on a short-term contract. ${ }^{56}$

Clinical faculty working under short-term contracts generally have, at most, a limited role in faculty governance. Some may be appointed to a faculty committee or invited to attend faculty meetings. However, marks of influence, like membership on an appointments committee or voting rights, are invariably absent. To a much greater degree than those employed under tenure, clinical-tenure, or long-term contract models, short-term contract clinical faculty are deployed in very specific ways. A few schools rely primarily, if not exclusively, on short-term contracts to operate their core clinical program. ${ }^{57}$ However, short-term contract clinical faculty are also often used in experimental clinics of limited duration or where the clinic is on uncertain or "soft" (i.e., external or potentially nonrecurring) funding.

For the overwhelming majority of short-term contract clinical faculty, there is no expectation of scholarly production. Over $85 \%$ of short-term contract clinical faculty report that they are not required to engage in scholarship as a condition of their employment. For the minority of shortterm contract clinical faculty who are required to engage in scholarship, $83 \%$ report receiving support for their scholarship, such as release time and access to research assistants. The absence of a scholarship expectation presumes that short-term contract clinical faculty will focus exclusively on teaching.

\section{Clinical Fellowships}

One variant of a short-term contract not included in the analysis in the preceding section is a clinical fellowship. Fellowships deserve separate attention and analysis because of their special features. A clinical fellowship is terminal, generally designed to prepare the fellows to enter the market for more permanent clinical teaching jobs. Many schools use clinical fellows to expand student clinic slots or provide summer coverage on clinic cases without creating additional permanent clinical positions. Some fellowship programs confer a degree, such as an LL.M. In exchange for teaching, fellows receive stipends or tuition waivers in programs that require fellows to enroll in coursework.

56. The ABA's accreditation standards recognize that a school may employ "a limited number of fixed, short-term appointments in a clinical program predominantly staffed by full-time faculty members, or in an experimental program of limited duration." ABA Accreditation Standards, Std. 405(c).

57. See Joy \& Kuehn, supra note 43 , at 183 n.2. 
Fellowship programs generally do not require scholarship as a condition of employment. However, clinic fellows who want to permanently enter the academy have an implicit pressure to produce scholarship at a level necessary to position them for a long-term appointment. Because they are not permanent members of the law school faculty, clinic fellows very rarely participate in faculty governance.

\section{CORE PRINCIPLES AND RECOMMENDATIONS}

Having described the vital role of clinical legal education to the academy and profession, as well as the various employment statuses according clinical faculty, Part II sets forth the core principles and recommendations which serve as the foundation of this Report. The four core principles are:

(1) Clinical education is a foundational and essential component of legal education;

(2) The legal academy and profession benefit from full inclusion of clinical faculty on all matters affecting the mission, function, and direction of law schools;

(3) There is no justification for creating hierarchies between clinical and non-clinical faculty; and

(4) The standards for hiring, retention, and promotion of clinical faculty must recognize and value the responsibilities and methodologies of clinical teaching.

The Task Force recommendation is that the four core principles are best realized by a unitary tenure-track model that recognizes and values the responsibilities and methodologies of clinical teaching in its standards for hiring, retention, and promotion. As explained in Part IB, many schools have attempted to comply with the ABA accreditation standard requiring "a form of security of position reasonably similar to tenure" by creating clinical tenure-track and long-term contract positions. These efforts have served the useful role of creating space within the academy to articulate standards for hiring, retention and promotion that are often a better fit for the demands of clinical teaching, service, and scholarship. However, the clinical tenure and long- term contract models do not best advance the core principles because in practice they have resulted in the creation of a class of permanently unequal clinical faculty members who have lesser governance rights and a diminished voice on important issues affecting the mission, function, and direction of their law schools. There is a continued role for short-term contracts and clinical fellowships to meet the demands of program development and the training and mentoring of new clinical 
faculty, but the Task Force recommends that such positions should be limited in number and tailored to the purposes that they are designed to serve. Part A that follows expands upon this Report's core principles, and how those principles are animated through clinical teaching, scholarship and service. Part B explicates the Task Force's recommendations and makes clear why, ultimately, the unitary tenure track model is the most appropriate model.

\section{A. CORE PRINCIPLES}

\section{Clinical Education Is A Foundational And Essential Component Of Legal Education.}

Clinical legal education is an essential component of a sound and complete legal education. Objective and thoughtful evaluators of legal education have independently identified and documented the value of clinical legal education. Although the case method of teaching is effective in instilling an understanding of legal analysis and reasoning, it is insufficient to ensure that students have a comprehensive understanding about what it means to be an effective and ethical lawyer. ${ }^{58}$ As the Carnegie Report has recently highlighted, the case method's reliance on static facts and law devoid of the complexity of actual legal practice serves to "prolong and reinforce the habits of thinking like a student rather than an apprentice practitioner, thus conveying the impression that lawyers are more like competitive scholars than attorneys engaged with the problems of clients." 59 The case method also provides little opportunity for students to "learn about, reflect on, and practice the responsibilities of legal professionals.", 60

In contrast, clinical legal education calls upon students to exercise sound professional judgment in a context where client problems, facts, legal rules, and ethical principles are integrated, unrefined, and fluid. ${ }^{61}$ In

58. Carnegie Report, supra note 24, at 28. In light of the Carnegie and Best Practices Reports, the case-dialogue method has come under renewed scrutiny. Criticisms surround an overemphasis, in the first two years of law school, on the case method to train students to think and effectively communicate points of view. Missing from the case-dialogue method is precisely what clinical programs are designed to do: give students experiences with clients, and help them consider issues of ethics, justice, and faimess in framing their legal arguments. Id. at 56-57.

59. Id. at 188 .

60. Id.

61. In a seminal article, Tony Amsterdam discusses the uniqueness of real client clinical legal education in the academy and how problems in the real client setting are infused with specific factual details, complex (with personal, economic, institutional, legal, and practical dimensions), and unrefined (unlike simulation materials or appellate cases where the facts are static, established, or already distilled). Anthony G. Amsterdam, Clinical Legal Education: A $21^{\text {st }}$ Century Perspective, 34 J. LEGAL EDUC. 612, 614-16 (1984). 
working with clients, law students gain the acumen for responsibilities essential to the profession. They begin to develop competence at integrating substantive legal research and analysis into their interpersonal communication, investigative, advocacy, mediation, negotiation, and collaboration efforts with acute awareness of their ethical imperatives. ${ }^{62}$ Through learning and applying doctrinal law to address the problems of clients, students meaningfully experience and understand the power, subtleties, and imperfections of legal doctrine and procedure. Importantly, by emphasizing critical reflection at each decisional stage of the representation process, clinical legal education allows students to apply past experience to future circumstances, develop their socio-professional identity, and better appreciate the multivariate dimensions of law and legal practice. In sum, clinical legal education does more than show students "how to think like a lawyer" and takes the next essential step in transforming students into effective and ethical lawyers.

Notably, clinical legal education also instills in students the arguably quintessential value of the legal profession: a duty to ensure access to justice for those who might otherwise go under-represented or unrepresented. Because most clinical programs serve financially or socially disadvantaged populations, clinical programs embody and reinforce this duty. Clinical programs provide countless hours of free or low-cost services to individuals, communities, governmental and public interest organizations through a variety of models such as direct representation, advocacy, reform initiatives, and community education. Through each of these representation models, clinical legal education gives voice to client goals and empowers clients to navigate difficult legal problems. Additionally, in field placement programs, students may work with governmental agencies and public interest organizations dedicated to ensuring justice. Students observe how institutions succeed or fall short of this promise and face the myriad of public policy considerations at stake. By ensuring access to justice for the unrepresented or underrepresented, clinical programs contribute to the common good by shaping our legal institutions to be responsive to, and behave equitably toward, those whom these institutions are bound to serve. Frequent interactions with these clients and causes sensitize students to their professional obligation to address the many barriers that prevent financially and socially disadvantaged individuals from access to legal assistance.

The benefits of clinical legal education also translate into tangible benefits to the legal profession. In training future lawyers to be both excellent and ethical, clinical legal education fulfills its core obligation to

62. MACCRATE REPORT, supra note 23, at $138-41$ (identifying and explicating the core competencies for the effective practice of law). 
the profession. It builds capacity in its students to meet the demands of practice and engage in lifelong professional development. Clinical legal education aims to accomplish the promise of the legal academy to infuse the profession with the lawyers that society yearns for: courageous, skillful, reflective, humane, and ethical professionals with a well-developed service and work ethic. ${ }^{63}$ Clinical legal education, when integrated with important non-clinical dimensions of the legal education enterprise, makes the legal academy whole.

\section{The Legal Academy And Profession Benefit From The Full Inclusion Of Clinical Faculty On All Matters Affecting The Mission, Function, And Direction Of The Law School.}

The unequivocal value of clinical legal education requires an equally unequivocal valuing of clinical law faculty as fully included members in the academic governance of law schools. Faculty involvement in academic governance has a long history and much to recommend it as a matter of academic policy. ${ }^{64}$ In law schools, faculty governance is required by ABA Accreditation Standards which state: "The dean and faculty shall formulate and administer the educational program of the law school, including curriculum; methods of instruction; admissions; and academic standards for retention, advancement, and graduation of students; and shall recommend the selection, retention, promotion, and tenure (or granting of security of position) of the faculty.",65

Equality entails full governance rights that ensure that the voices of clinical faculty directly, consistently, and effectively contribute to the law school's mission, curricular development, faculty development, and

63. See Carnegie Report, supra note 24, at 23 ("students must learn abundant amounts of theory and vast bodies of knowledge, but the 'bottom line' of their efforts will not be what they know but what they can do. They must come to understand thoroughly so they can act competently, and they must act competently in order to serve responsibly.").

64. Unlike the pyramidal hierarchies of private industry, authority in a typical university is divided between a central administration and one or more collegial bodies. N.L.R.B. v. Yeshiva University, 444 U.S. 672, 680 (1980) (citations omitted). This system of shared authority evolved from the medieval model of collegial decision making in which guilds of scholars were responsible only to themselves. Although faculties have been subject to extemal control in the United States since colonial times, traditions of collegiality continue to play a significant role at many universities. Id. The U.S. Supreme Court stated that "[ $t]$ he 'business' of a university is education, and its vitality ultimately must depend on academic policies that largely are formulated and generally are implemented by faculty governance decisions." Id. at 688. Academics have the unique expertise needed to govern academic affairs at an institution of higher learning: " $[t]$ he faculty 'are the people who ought to decide educational matters from the setting of the curriculum to the hiring and tenuring of professors - because they have the disciplinary training and knowledge to make informed decisions in those areas." Susan A. Liemer, The Hierarchy of Law School Faculty Meetings: Who Votes? 73 U.M.K.C. L. REV. 351, $365-66$ (2004)(quoting Joan Wallach Scott, The Critical State of Shared Governance, ACADEME (July-Aug. 2002)).

65. A.B.A. Accreditation Standards, Std. 205. 
academic standards. Governance rights for clinical faculty should extend to all aspects of the legal academy: committee appointments and chairpersonships, voting rights, hiring of faculty colleagues, promotion and retention decisions, and all other important faculty governance functions. By participating fully in faculty governance, clinical faculty members can most meaningfully contribute to the academy's mission, function, and direction, and its delivery of legal education.

Full governance acknowledges that a clinical faculty member not only possesses the abilities to evaluate matters essential to the law school, but that including clinical faculty fully in faculty governance can enhance the overall quality of collective decisions. Clinical faculty provide perspective and voice essential for a thoughtful, balanced, and informed discussion on the character and future of the legal academy. Apart from representing a unique pedagogical viewpoint, clinical faculty are well-situated to observe students' socio-professional development and to give voice to the concerns of the legal profession, the bench, and the surrounding communities. With full governance rights, the perspectives derived from clinical teaching and articulated by clinical faculty are thus appropriately blended into the mix of faculty viewpoints.

Full faculty governance rights are especially important as law schools embark on curricular and other pedagogical reforms in light of the Carnegie Report and other examinations of the shortcomings of traditional law school education. As long as the voices of clinical faculty are institutionally muted, lawyering skills and professional values will remain at the margins of legal education. If law schools seek to transform themselves in a manner that truly responds to the legal profession and societal needs in general, they will benefit greatly by including clinical educators in an equal role in institutional governance.

No decisions are as important to the mission, function, and direction of law schools as decisions about hiring, retention, and promotion of law school faculty members. Hiring, retention, and promotion decisions reflect the priorities of a law school through its allocation of resources. Such decisions also shape a law school's identity and constitute the body of faculty members who will govern other important decisions affecting the law school. To exclude clinical faculty members from hiring, retention, and promotion decisions disenfranchises them in ways that have deep and longstanding effects on the shape and direction of a law school program. A vision of equal governance cannot exclude clinical faculty members as a class from faculty governance on those critical judgments. 
3. There Is No Justification For Creating Hierarchies Between Clinical And Non- Clinical Faculty.

In excluding clinical faculty from full governance over issues involving the mission and direction of law schools, especially faculty hiring, retention, and promotion, law schools have created hierarchies in which one class of permanent faculty members makes decisions affecting another class of permanent members, often without reciprocity. Such hierarchies exist without reasonable and adequate justification.

The primary argument offered for excluding clinical faculty from full governance rights in hiring, retention, and promotion of non-clinical faculty members is that clinical faculty members lack the expertise to judge nonclinical faculty members in the areas of teaching, scholarship, and service because clinical faculty members' teaching, scholarship, and service requirements differ in important respects from those of non-clinical faculty. The expertise rationale is most often raised in the context of the evaluation of scholarly potential and achievement. The expertise argument goes that because many clinical teachers do not produce scholarship at all or produce scholarship that differs from that of traditional classroom professors, the limited role of clinical faculty in the hiring, promotion, and tenure of nonclinical faculty is appropriate.

However, this presumed lack of expertise is not always applied uniformly. Although the lack of expertise across faculty sectors is sometimes used to justify the disenfranchisement of clinical faculty, nonclinical faculty members are often presumed qualified to judge the hiring, retention, and promotion of clinical faculty. Such uneven application of the "expertise" justification for disenfranchising some faculty members but not others reveals its irrationality.

The expertise rationale is also flawed in its underlying assumptions, which fundamentally misrepresent the nature and complexity of hiring, retention, and promotion decisions. The expertise rationale ignores the many important ways in which votes on hiring and, to a lesser extent, retention and promotion are expressions of institutional values and identity, and it underestimates the ability of all faculty members to use tools like peer and student assessment to aid the exercise of their judgment. The expertise rationale assumes that the ability to judge the potential and performance of other faculty members inheres in faculty status, rather than developing over time and through the repeated experience of reviewing potential candidates, hiring them, and assessing how they perform. It ignores the important role that peer evaluation of scholarship plays in assisting faculty members' judgment of promotion and tenure decisions when they evaluate scholarly achievement outside their area of legal expertise. It also ignores the fact that votes on hiring are often choices 
among equally well-qualified candidates about the deployment of resources and institutional fit, issues in which all permanent faculty members have a stake and can capably evaluate.

Paradoxically, the inequality in governance rights between clinical and non-clinical faculty has become more extreme and less justifiable as law schools have striven to secure the job security of clinical faculty in the academy. To comply with ABA regulations that require "a form of security of position reasonably similar to tenure," many schools have created parallel promotional tracks, such as clinical tenure-track or presumptively-renewable long-term contract promotional tracks. Like tenure, these parallel promotional tracks create a system of probationary appointment that allows for evaluation and acculturation into law school teaching before being voted into the permanent (or presumptivelypermanent) ranks of the law school faculty. To deny equal governance rights to presumptively-permanent members law school clinical faculty creates a sector of the faculty with long-term institutional ties and yet without a voice on important matters affecting the future mission, identity, and direction of the law school.

A limited number of schools have attempted to avoid this hierarchy by creating separate spheres of faculty governance in which clinical faculty members alone may vote on the hiring, retention, and promotion of other clinical faculty members. While this approach escapes the problem of hierarchy, it exaggerates the differences between clinical and non-clinical faculty members and ultimately impoverishes legal education as a whole. Clinical faculty members who have committed to a career of clinical teaching are typically involved in all aspects of the life of an institution. Although they may balance and carry out their professional and academic obligations in different ways than traditional non-clinical faculty members, the differences are not so great as to deprive clinical faculty of the ability to understand and appreciate their non-clinical colleagues or to be understood and appreciated by them. Moreover, the entire law school faculty shares a mission to educate law students as competent and ethical members of the legal profession.

The parsing of faculty governance into separate spheres impedes the understanding, appreciation, and integration among the component parts of legal education and makes that common mission more difficult to achieve. Indeed, the separation of faculty governance into programmatic spheres enables faculties to avoid working together to formulate a thoughtfully integrated allocation of the law school's resources. Legal education is better served by the elimination of both irrational hierarchies and separate spheres of faculty governance.

The parsing of faculty into separate promotional spheres also results in irrational hierarchies. Too often, clinical tenure track and long-term 
contract statuses have also been used to diminish clinical faculty role in institutional governance. Most disturbingly, the creation of separate promotional tracks for clinical faculty has been used to justify maintaining a separate class of faculty members to whom law schools commit as presumptively-permanent members of the faculty, yet to whom schools deny full inclusion in faculty governance. This kind of hierarchical organization of faculty governance within the legal academy cannot be justified by the differences in clinical teaching, scholarship, and service. Perpetuating this unequal governance scheme is detrimental to legal education as a whole.

4. The Standards For Hiring, Retention, And Promotion Of Clinical Faculty Must Recognize And Value The Responsibilities And Methodologies Of Clinical Teaching.

To fully integrate teaching of lawyering skills and professional values into the academy, law schools must recognize that the different goals and methods of clinical legal education may entail hiring clinical faculty with different kinds of background and aspirations from traditional faculty hires. They must also value those differences by evaluating and supporting clinical faculty's teaching, scholarship, and service in ways that are different from the evaluation and support of the academic work of nonclinical faculty. Pressing clinical faculty into a mold used to judge the excellence of faculty members with different job requirements limits the best use of a clinical faculty member's experiences, perspectives, skills, and interests. This works to the academy's and the profession's disadvantage.

Clinical faculty have teaching demands and professional responsibilities that differ from those of traditional doctrinal faculty. As described in Part I, clinical teaching is time-intensive and individualized, and its time demands generally do not diminish over repeated semesters of teaching the same clinical course. Clinical scholarship arises from a different perspective on law, often embodies a different voice, and is sometimes produced for different audiences or in different forms than traditional doctrinal scholarship. The academic service requirement of clinical faculty is augmented by the social justice mission of clinical legal education, which demands investment in building and developing ties in the local community. Consequently, the optimal balance between teaching, scholarship, and service for clinical faculty may differ from the optimal balance for their non-clinical colleagues.

Recognizing and valuing the different responsibilities and methodologies of clinical teaching begins with appropriate hiring decisions. Faculty hiring is often carried out within the parameters of shared 
assumptions about what factors will predict productive scholarship and good classroom teaching. Typically, appointment committees look for markers of academic success such as graduation from elite law schools, prestigious work in federal clerkships, post-graduate degrees in other disciplines, and an already-established record of law review publication prior to entry on the job market. When job candidates visit a law school, they give a "job talk," which is used as an indictor of their success as a teacher in large classroom settings and their ability to articulate and defend their scholarship.

In clinical hiring, the assumptions about who will make a good clinical faculty member and what markers will predict that member's success are less entrenched. To the extent that clinical hiring is controlled by appointment committees dominated by professors with little exposure to the special requirements of clinical teaching, a law school must develop a clear sense of the goals and methods of its clinical program and the range of factors that will signal success in that program. This should lead to sound standards for identifying and selecting the best hire for the clinical program.

Once hired, clinical faculty members also must be evaluated in ways that appropriately value the differences in their teaching and service responsibilities and are sensitive to the unique time demands of clinical teaching. To the extent that clinical faculty are encouraged to develop a scholarly voice from their perspective embedded in practice, their scholarly agenda can be more easily integrated with their clinical teaching and policy work. However, if the scholarship expected of them has little connection to actual cases handled or to the goals of the groups being served in a clinical program, the use of traditional scholarship standards can widen the chasm between the scholarship of clinical faculty and the work they do on behalf of their clients, the bench, and the bar.

Schools may also choose to base tenure decisions on meeting appropriate standards for excellence in clinical teaching or service to the community outside the law school that are grounded in clinical pedagogy and evidenced by clinic activities. Such standards have been developed in schools employing a clinical tenure track and can provide guidance on how to articulate standards for excellence in clinical teaching for purposes of tenure, promotion, and post-tenure review. Although there may be institutional barriers to granting unitary tenure on the basis of teaching or service alone, a school may decide to weigh such factors more heavily in tenure decisions for clinical faculty as compared to their non-clinical colleagues, recognizing that the balance of time and effort clinical legal education requires in the areas of teaching and service is greater.

Regardless of the criteria used, it is important to recognize the special time demands of clinical work by providing support that is adequate for 
clinical faculty to meet the retention and promotion standards. If those standards are based on the expectation of scholarly production at the same level as traditional classroom teachers, schools must provide structural support that allows clinical faculty the ability to disengage from clinic work and engage in scholarship. Such support can include pre-tenure research leaves, temporary hiring for summer case coverage, and pre-tenure teaching load reductions. Schools may also want to consider reducing the amount of scholarship they expect clinical faculty to produce for purposes of tenure.

\section{B. TASK FORCE RECOMMENDATIONS}

The recommendation of the Task Force is that full-time law faculty teaching in clinical programs should be predominantly employed under a unitary tenure-track model. The touchstone for this recommendation is equal treatment, a concept that requires the extension of full inclusion of clinical faculty in institutional decisions that affect the mission, function, and direction of their law schools, including important decisions related to faculty hiring. To meet the challenges of fully preparing law students for the ethical and competent practice of law, law schools must recognize the value of clinical legal education by extending to clinical faculty the security of position, academic freedom, and governance rights that come with a unitary tenure-track system, while recognizing a clinical faculty member's different imperatives as they regard teaching, scholarship, and service.

No status model in the legal academy other than unitary tenure-track consistently provides security of position, full inclusion in faculty governance, and protection for academic freedom. Other status models that schools have created to comply with $\mathrm{ABA}$ regulations requiring conditions "reasonably similar" to tenure have been instrumental in helping to articulate and define hiring, retention, and promotion standards that recognize and value the differences in clinical teaching, scholarship, and service. However, these models have failed to fully integrate clinical faculty members into governance over important decisions affecting the mission, function, and direction of law schools. Moreover, the creation of separate clinical tenure tracks and presumptively-renewable long-term contracts have created permanent classes of faculty members with unequal status, power, and voice in faculty governance. Exceptions to unitary tenure-track clinical positions are warranted in limited circumstances to allow the expansion of clinic slots for students in experimental clinical programs and to provide training for new clinical faculty. These exceptions should be restricted in number, duration, and purpose, should not be used to create a permanent underclass of faculty members. 
1. The Benefits Of Clinical Legal Education Are Best Achieved By Predominantly Employing Full-Time Clinical Faculty On A Unitary Tenure Track That Recognizes And Values The Responsibilities And Methodologies Of Clinical Law Teaching.

The Task Force's recommendation in favor of the unitary tenure-track model emerges from the well-acknowledged importance of tenure in education. Tenure confers "freedom of teaching and research and of extramural activities, and . . . a sufficient degree of economic security to make the profession attractive to men and women of ability." ${ }^{.66}$ The unitary tenure-track model encourages the values promoted in clinical legal education. The tenure model also provides the security of position and academic freedom protections that free a professor to espouse positions on issues, and indeed may impose upon clinical faculty "an enhanced obligation to pursue individual and social justice." ${ }^{67}$ Ensuring equal security of position is a testament to the academy's commitment to its clinical faculty and the value they bring to the legal academy and profession. By extending to clinical faculty the security of position provided by tenure, law schools facilitate retention, instill in clinical faculty a commitment to the institution, and attract the best and brightest lawyers to careers as clinical educators.

It is widely accepted that tenure best promotes the scholarship, teaching, and service of faculty and also serves the interests of the legal academy by attracting the most qualified professors with a lifelong commitment to education. The ABA and the AALS require that each law school have an established policy with respect to academic freedom and tenure and endorse the text of the "1940 Statement of Principles on Academic Freedom and Tenure" of the American Association of University Professors (AAUP). The AAUP Statement declares that a university teacher is entitled to freedom of teaching, research, and extramural activities and that tenure is the means to achieve those ends. Both that Statement and a later AAUP Interpretative Comment declare that even pretenure teachers should have the academic freedom of other members of the faculty and that the protection of academic freedom also applies to all others who exercise teaching responsibilities, such as part-time faculty and

\footnotetext{
66. AM. ASS'N OF UNIV. PROFESSORS, Statements of Principles on Academic Freedom and Tenure, in POLICY DOCUMENTS AND REPORTS $\left(10^{\text {th }}\right.$ ed. 2006), available at http:/www.aaup.org/AAUP/pubsres/policydocs/contents/1940statement.htm. As the American Association of University Professors states, this freedom and security make tenure "indispensable to the success of an institution in fulfilling its obligations to its students and to society." Id.

67. Ass'n of Am. Law Schools, Statement of Good Practices by Law Professors in the Discharge of their Ethical and Professional Responsibilities, 2011 AALS HANDBOOK 133 (2011), available at http://www.aals.org/about_handbook_sgp_eth.php.
} 
teaching assistants. ${ }^{68}$ The AALS similarly states that faculty members entitled to academic freedom include those not on tenure track but "engaged in teaching or scholarship, including work in clinical or research and writing program."

Clinical faculty who are tenured on a unitary tenure track model are most empowered to advance the institutional interest of "transmitting, evaluating, and extending knowledge."70 Security of position allows clinical faculty to most effectively deliver to students and the profession the true value of clinical legal education. The success of clinical legal education in reaching its pedagogical objectives depends on sustained and predictable connections with, and an understanding of, the local communities, the bench, and the bar. Because tenure offers the promise of a long-term appointment, the tenured clinical professor enjoys the opportunity to become deeply in both the academy and the community. The ability to engage deeply in the community expands the reach of the professor's contributions while enriching the ideas and perspectives brought back into the classroom. As the expertise and stature of the professor grow, so too do the sophistication and geographical boundaries of service activities. Leadership development and expanded community networks accompany position stability.

Optimal academic freedom also flows from the security of position that a unitary tenure-track affords. Clinical educators commonly undertake representation, scholarship, or service projects that challenge the status quo. ${ }^{71}$ Explicit and uncompromised academic freedom is essential to allow clinical faculty to effectively engage in what they teach, as well as their scholarly and representation endeavors. Because clinical coursework invariably affect those outside of the law school, clinical professors are the members of the legal academy most vulnerable to attacks on and challenges to their educational decisions and, ultimately, their job security. Placement of clinical professors onto a unitary tenure track best protects clinical faculty from reprisals and encourage innovation and risk-taking in their lawyering, teaching, and scholarship.

The security accompanying tenure develops seniority and influence and institutionalizes the presence of clinical faculty in decision making that most affects a law school. With equal influence in governance - including

68. AM. ASS N OF UNIV. PROFESSORS, supra note 66.

69. Ass'n of Am. Law Schools, Statement of the Association of American Law Schools in Support of Academic Freedom for Clinical Faculty, 2011 AALS HANDBOOK 145 (2011), available at http://www.aals.org/about_handbook_sgp_clin.php.

70. AM. ASS'N OF UNIV. PROFESSORS, Recommended Institutional Regulations on Academic Freedom and Tenure, in POLICY DOCUMENTS AND REPORTS (10 ${ }^{\text {th }}$ ed. 2006), available at http://aaup.org/AAUP/pubsres/policydocs/contents/RIR.html.

71. See Robert R. Kuehn \& Peter A. Joy, An Ethics Critique of Interference in Law School Clinics, 71 FORDHAM L. REV. 1971, 1975-92 (2003). 
hiring decisions, curricular issues, and other institutional matters - clinical faculty are best situated to contribute to the academy's direction and delivery of legal education. Equal governance rights give voice and influence to the unique perspectives clinical faculty members bring to the table. The unitary tenure-track model helps infuse the concerns and perspectives of clinical faculty into decisions about the law school, and encourages movement toward the appropriate integration of skills and doctrinal teaching.

Equally important to institutionalizing clinical faculty voices in governance is the need to develop hiring, promotion and retention standards that respect the responsibilities and methodologies of clinical law teaching. This latter imperative is especially critical in crafting scholarship requirements. The tenure-track model invariably includes a requirement to fulfill and pursue a scholarly agenda. Without question, the requirement of scholarship advances the legal academy's mandate to create, uncover, cultivate, evolve, and expand knowledge for the public good. ${ }^{72}$ By extending this mandate to faculty who teach in clinical courses, the unitary tenure-track model acknowledges the intellectual value clinical professors can bring to legal education, the law, economic, social, and political policy. Clinical faculty members with scholarship standards identical to nonclinical faculty have succeeded on unitary tenure-tracks and continue to do so, producing work that is of same intellectual quality, rigor, and scope.

Despite those successes, an abiding question is how scholarship requirements might be realized in ways that appropriately recognize both the contributions that a clinical faculty member's intellect and experiences can bring to a broader range of audiences, and the unique time demands of clinic teaching. An overly strict application of uniform standards may unduly distance the clinical author from experiences as a lawyer, supervisor, and teacher. It may direct the author toward academic audiences at the expense of others who would benefit from the insights of clinical scholars. Further, an overemphasis on research and writing may skew clinical faculty hiring toward individuals who show the greatest promise of excellence as traditional scholars, while giving insufficient attention to teaching, supervisory, and practice competence. The opportunity to connect with, and expand on ideas and experiences derived from the clinical domain creates a symbiosis between a faculty member's scholarship and teaching. Schools should implement a faculty scholarship policy that explicitly rewards the type of work relevant to clinical education and the legal profession.

72. See generally, AM. Ass'N OF UNIV. ProfESSORS, 1915 Declaration of Principles on Academic Freedom and Academic Tenure, in POLICY DOCUMENTS AND REPORTS (10 th $\mathrm{ed}$. 2006), available at http://www.aaup.org/AAUP/pubsres/policydocs/contents/1915.html. 
Going further, schools might also adopt alternatives to requiring that clinical faculty scholarship be of the identical scope, length, and quantity as other faculty. In revising or developing scholarship standards, schools should consider adjusting the number of required articles or the schedule of production, or count alternative forms of writing. Finally, schools might adjust tenure requirements that place primacy emphasis on teaching and service excellence.

Under the ideal tenure standard, any or all of these alternatives would be adopted to account for the important and often unique obligations to which clinical faculty direct their time, expertise, and intellectual focus. Moreover, any of these alternatives best leverage the intellectual capacity and expertise of clinical faculty in furtherance of the academy's obligations to the legal profession and public. Regardless of the policy adopted, the importance of making it explicit cannot be overstated. This is especially true in circumstances that would allow for advancement based on scholarship directly tied to clinical faculty member's experiences and perspectives or to excellence in clinical teaching or community service.

2. Separate Clinical Tenure And Long-Term Contract Models Are Inferior Because They Have Usually Resulted In A Permanent And Unequal Class Of Faculty Members With Less Secure Job Status And Diminished Governance Rights.

Although ABA Accreditation Standard 405(c) permits the employment of full-time clinical faculty members in "a form of security of position reasonably similar to tenure," the implementation of the "reasonably similar" standard has in the majority of cases failed to afford clinical faculty adequate governance rights with respect to important matters affecting the mission, function, and direction of law schools. The Task Force does not doubt that the majority of law schools that have implemented systems of clinical tenure and long-term contracts have done so in good faith and in an effort to comply with $A B A$ regulations. In fact, the ABA interpretation of Standard 405(c) specifically endorses those choices, defining "reasonably similar" to include "a separate tenure track or a program of renewable long-term contracts." ${ }^{73}$ However, the interpretations also require that full-time clinical teachers shall be afforded "participation in faculty meetings, committees, and other aspects of law school governance in a manner reasonably similar to other full-time faculty members." ${ }^{\prime 74}$ Many schools have interpreted this requirement to permit the

73. AM. BAR ASS'N, 2011-2012 STANDARDS AND RULES OF PROCEDURE FOR APPROVAL OF LAW SCHOOLS, Interpretation 405-6 (Am. Bar Ass'n 2011).

74. AM. BAR Ass'N, supra note 73, at Interpretation 405-8. 
school to deny non-tenured or clinical tenure-track faculty full voting rights and full participation in faculty committees, especially on matters of faculty hiring.

As a result of these limitations on faculty governance, clinical status models such as clinical tenure or long-term contract fall short of the intended benefits of the tenure system. In many cases, governance rights and perquisites of clinical tenure-track faculty are notably less than unitary tenure-track or tenured faculty. As the CSALE survey data highlights, the differential treatment of clinical faculty becomes most prominent when comparing clinical faculty on a unitary tenure track, who universally enjoy full incorporation into law school faculties, with their colleagues on a separate clinical tenure track. A clinical tenure-track model ostensibly creates a permanent job status for clinical faculty while recognizing the unique attributes of clinical teaching. However, the majority of faculty in a clinical tenure model are permanently disenfranchised on important issues that affect the mission and direction of the law school, especially on the crucial issues of faculty hiring.

The long-term contract model fails in those respects as well. Along with the diminished voice and influence that results from lessened governance rights, long-term contract clinical faculty have even weaker assurances of academic freedom, and are left vulnerable to internal and external interference.

Moreover, each status model other than tenure communicates to students that the role clinical faculty have in their professional formation can never be as valuable as that provided by non-clinical faculty. ${ }^{75}$ Apart from the surface markers of inequality, each of these other models institutionally preserves a lower status for clinical faculty. The absence of a meaningful governance role fortifies the presumption that clinical faculty contribute less intellectual value to institution-building. The move toward a unitary tenure-track model for clinical faculty ensures that they will be fully empowered to advance the academy's mission of "transmitting, evaluating, and extending knowledge ${ }^{, 76}$ and not be permanently entrenched in faculty positions with diminished status, security, governance, and academic freedom.

75. Carnegie Report, supra note 24 , at $87-88$ (arguing that the failure to fully incorporate clinical faculty and clinical courses school sends a message to students that such courses are not valued).

76. AM. ASS'N OF UNIV. PROFESSORS, supra note 65. 
3. Short-Term Contracts And Clinical Fellowships Should Be Reserved For Limited Situations Tailored To The Purposes That They Are Best Designed To Serve.

In recommending that law schools adopt a predominant tenure model for their clinical programs, the Task Force accepts the continued use of the short-term contract and clinical fellowship models, so long as they are limited in number and duration and tailored to the limited purposes they are designed to serve. Short-term contract and clinical fellowship models may be more cost-effective and flexible from an institutional perspective, but they fail to provide meaningful assurance of security of position, academic freedom, or governance rights. To staff a clinical program predominantly with short-term contract appointments or clinical fellows would violate current ABA Standard 405(c), which states that its requirement of status "reasonably similar to tenure . . . does not preclude a limited number of fixed, short-term appointments in a clinical program predominantly staffed by full-time faculty members, or in an experimental program of limited duration." $" 77$

When a clinical program is staffed predominantly by short-term employees, all aspects of the clinical program suffer. For a clinical program to meet the demands of teaching law students to practice law, clinical faculty need the long-term experience to understand, interpret, and predict local practice. Moreover, to build long-standing ties with a local community, and especially its field placement program, a clinical program needs long-term faculty with a personal and professional investment in the community. And a solid base within a law school is required to protect a clinical program's advocacy from interference.

Yet short-term contract and clinical fellowship positions, when used in limited form, can serve a valuable purpose in the development of clinical legal education. Short-term contracts can enable clinical programs to expand into new areas or take on limited projects on soft-money grant funding. Such experimental and limited duration projects can provide valuable service to a community, open up clinic slots to additional students, and strengthen and enliven a clinical program that is built on a solid foundation of tenured and tenure-track clinical faculty members.

Furthermore, the Task Force recognizes the value of fellowship programs as a mechanism for serving clients and students, and for moving lawyers into the academy as clinical faculty. Providing a thoughtfully developed training ground for new clinical faculty who are making the transition from practice to clinical teaching is even more important as a corollary to the recommendation for predominant use of the unitary tenure-

77. AM. BAR ASS'N, supra note 73, at Standard 405(c). 
track model. Clinical fellowships can allow opportunities for mentorship in clinical teaching and provide entry-level candidates with the time and intellectual space to craft a scholarly agenda that is tied to and symbiotic with clinical teaching and service.

\section{TENSIONS REGARDING THE UNITARY TENURE-TRACK MODEL FOR CLINICAL FACULTY}

The proposition that law schools move toward a unitary tenure-track model as the predominant model for clinical faculty raises unavoidable tensions. These tensions emerge from the current debate within the academy and the bar over the regulation of law schools; within institutions as to the costs of clinical legal education and the institutional impact of full governance, academic freedom, and scholarship for clinical faculty; and within the clinical legal education community itself about the impact of a tenure model on the core pedagogical and social justice missions of clinical legal education. While the Task Force recognizes these tensions, it does not believe that they pose insurmountable obstacles to a recommendation that the primary model for full-time clinical faculty should be a unitary tenure track.

\section{A. TENURE AND REGULATION OF THE SECURITY OF POSITION}

The ABA Standards governing clinical faculty members have been a source of tension for over twenty years. ABA Accreditation Standards affect clinical legal education in at least two significant ways: (1) by requiring that all law schools offer substantial opportunities for live-client or other real-life practice experience, ${ }^{78}$ and (2) by requiring that schools afford clinical faculty a form of security of position and non-compensatory perquisites reasonably similar to other full-time faculty members. ${ }^{79}$ At present, these standards are interpreted to "include a separate tenure track or a program of renewable long-term contracts," which is in turn

\footnotetext{
78. Current Standard 302(b)(1) requires that a law school offer "substantial opportunities" for "live-client or other real-life practice experiences, appropriately supervised and designed to encourage reflection by students on their experiences and on the values and responsibilities of the legal profession, and the development of one's ability to assess his or her performance and level of competence." Id. at Standard 302(b)(1). These practice experiences may be accomplished through clinics or field placements, but a school is not required to offer these experiences to every student or accommodate every student requesting enrollment in any particular practice experience. Id. at Interpretation 302-5. The AALS also requires each member school to provide significant opportunities for instruction regarding professional skills. Bylaws of the Association of American Law Schools, Section 6-7c.

79. Id. at Standard 405(c).
} 
interpreted to mean "at least a five-year contract that is presumptively renewable or other arrangement sufficient to ensure academic freedom."

Although the ABA has consistently sought to strengthen rather than weaken the standards governing the status and governance rights of clinical faculty, it has not always been able to count on the ABA Accreditation Committee to rigorously implement the Standards. In 2005, the Council of the ABA Section of Legal Education and Admissions to the Bar (hereinafter, "Council") decided to revisit ABA Accreditation Standard 405. because of concerns that the ABA Accreditation Committee's approval of schools with three-year contracts and no presumption of renewal was inconsistent with the meaning of "long-term contract." This resulted in a new sentence in Interpretation 405-6 explaining that a "'long-term contract' means at least a five-year contract that is presumptively renewable or other arrangement sufficient to ensure academic freedom." However, one institution publicly rejected this interpretation, claiming that its use of oneyear nonrenewable employment contracts with clinical faculty was sufficient to meet the "security of position" standard in Standard 405(c).$^{81}$ Relying on the new phrase "or other arrangement sufficient to ensure academic freedom," the Accreditation Committee approved one-year contracts for clinical faculty at that school based on the fact that the university had an academic freedom policy that the law school followed. ${ }^{82}$

In addition, there are ongoing efforts by the American Law Deans Association (ALDA) to eliminate all references to security of position and faculty governance rights and to simply require a law school to establish and maintain conditions adequate to attract and retain a competent faculty. In both 1999 and 2003, the Council rejected proposals to eliminate all references in Accreditation Standard 405 to tenure, both for clinical and non-clinical faculty. ${ }^{83}$ Those promoting the elimination of all the standards regulating security of position, including tenure, argue that the $A B A$ is improperly intruding on the employment decisions of law schools and that market forces should be allowed to dictate the status of clinical and other law school faculty. ${ }^{84}$ They suggest that paying clinical professors less and

\footnotetext{
80. Id. at Interpretation 405-6.

81. See Joy \& Kuehn, supra note 43, at 224-25.

82. Id. at 225.

83. Id. at 215-16, 218 .

84. Cf. Statement by the Bd. of Dirs. of Am. Law Deans Ass'n to the Am. Bar Ass'n Accredidation Policy Task Force (Jan. 3, 2007), available at http://www.americanlawdeans.org/images/ ALDA_Board_Statement_1-5-07_.pdf (stating that "a law school should be allowed to satisfy the minimum requirements of a sound legal education in the way it sees fit," that "[ $t]$ he decisions about the terms and conditions on which a law school or university hires its faculty and other employees should remain with the individual law school," and seeking to strike or diminish ABA Accreditation Standard 405(c) which requires law schools to afford full-time clinical faculty members a form of security of position reasonably similar to tenure.").
} 
not being required to provide a form of security of position or governance rights would allow law schools greater opportunities for clinical program expansion and experimentation.

Finally, there are some, outside and within the clinical legal community, who question the value of tenure as an institution. Critics of tenure argue that it tends to homogenize legal education by controlling the development of law professors in a lengthy pre-tenure period, allows some professors to "rest on their laurels" after achieving tenure, and places an undue emphasis on scholarly production at the expense of excellent teaching and service. Extending traditional tenure to clinical faculty under a unitary tenure system, some argued, would aggravate the problems with legal education, rather than contribute to reform.

Despite these criticisms, the Task Force recommends a unitary tenuretrack system for clinical faculty as long as tenure remains the predominant form of job security, governance, and academic freedom within the legal academy. Although framed broadly in principle, attempts to deregulate the security of position in law schools still target the ABA's security of position provisions designed to protect clinical faculty. It is not surprising that attacks on security of position would be more successful when launched against less powerful and more vulnerable sectors of law school faculties. If deans want to promote experimentation and diversification of law school programs, they should work to bolster the diversity of voices that contribute meaningfully to faculty governance over curricular matters, admissions, and appointments, instead of working to further marginalize clinical legal education and its faculty.

\section{B. COSTS}

A second point of tension within law school programs regards the financial costs of placing or moving clinical faculty to a unitary tenuretrack. On the one hand, it is argued that because of the lower facultystudent ratios that clinical legal education requires, it is more expensive than other forms of legal education. To staff a clinical program with tenured or tenure-track faculty, institutions may have to devote more resources to support these positions. Moreover, as the trend continues to voluntarily expand experiential opportunities for law students in response to the Carnegie and Best Practices Reports, institutional costs may rise as schools expand their clinical programs.

These arguments are usually mounted on the assumptions that traditional tenure-track professors exclusively teach large-enrollment courses that are more cost-effective and that clinical professors teach only small-enrollment courses. These assumptions, however, do not always hold. The early law school model of a few full-time faculty members with 
large teaching loads, high student/faculty ratios, and high adjunct utilization is no longer in effect at most law schools. ${ }^{85}$ However, the costs and benefits of upper-level small enrollment courses or small seminars developed around the research interests of tenured and tenure-track faculty are rarely placed under cost-benefit scrutiny by those making such arguments in reference to clinical legal education. To the extent that clinical professors on a unitary tenure-track are permitted or required to teach traditional large-enrollment courses above and beyond their clinical teaching, the costs of maintaining them on unitary tenure-track lines can be partially recovered through the savings of having those courses covered.

Cost vigilance is a valid concern. As the cost of legal education for students continue to rise, law schools are rightfully concerned about resource allocation - especially during acutely adverse economic times. However, such financial analysis should not be focused solely on the clinical faculty, a discrete subset of historically marginalized institution members. Any cost rationale must take into account a host of other costs incurred in the delivery of a sound legal education. The argument that including clinical professors on a unitary tenure-track costs more assumes a baseline of inferior status for clinical faculty. Moving to a unitary tenuretrack model will require a larger financial outlay for institutions currently providing minimal support for non-tenured or non-tenure track clinical faculty who earn less salary or other perquisites than comparable nonclinical faculty. The bottom line is that institutions must look to all aspects of the institution to weigh the cost tension with intellectual honesty and move beyond the myopic invocation of costs only as it relates to clinical legal education.

\section{CLINICAL FACULTY SCHOLARSHIP}

Traditional tenure standards privilege scholarship highly, often to the diminishment of excellence in teaching and commitment to service. Clinical legal education requires time-intensive teaching and deep investment in the community that can seem inimical to scholarly production in the amount and type required under traditional tenure standards. Given these differences, some find it difficult to envision a unitary tenure-track system working for clinical faculty.

Of particular concern within the clinical community is that the emphasis on scholarly production will detract from some of the core missions of clinical legal education: teaching students to be ethical and effective practitioners who work to ensure access to justice in the context of advocating on behalf of those underrepresented or unrepresented. Many 
within the clinical community view traditional law review scholarship as doing little to advance the goals and values of clinical legal education. To the extent that institutions resist re-defining scholarship requirements to responsively account for the work that clinical faculty perform, two unfortunate results are likely to occur. One unfortunate result is that clinical faculty default to writing "safe" scholarship - scholarship that might bear little relationship to their expertise or experience. Tenured or tenure-track clinical faculty members often recount the Hobson's choice they face when deciding what type of scholarship to pursue. Although the norm is that one should write in one's area of strength, clinical faculty fear that their work will not be viewed as sufficiently "scholarly" when evaluated by an overwhelmingly non-clinical promotion and tenure committee. A second unfortunate result is that clinical programs will scramble to reconfigure their clinic structure to accommodate the demands of scholarly production, rather than basing decisions about clinic design on the requirements of sound clinical pedagogy and service to clients and communities.

Even for clinical faculty with well-defined and more traditional scholarly agendas, the nature of clinical teaching does not lend itself to maintaining structured time for immersion in scholarship. The absence of efficiencies through repetition, the time-intensive one-on-one supervision of students, and the inability to control the pace of legal matters create challenges in time management and intellectual focus. In addition, time periods that other faculty members typically devote to research and scholarship, like summer breaks, are often consumed by responsibilities clinical faculty have to their clients, the bench, and the bar.

The Task Force has responded to these concerns by insisting that standards for hiring, retention, and promotion under a unitary tenure-track system value the unique aspects of clinical pedagogy and take them into account by a combination of efforts, such as: providing institutional support for clinical faculty scholarship in the form of summer case coverage or additional leave time; encouraging the development of the unique perspective and voice that clinical faculty bring to scholarship; considering for tenure purposes a wider range of types of written work, such as policy papers, briefs, and training materials; and developing and articulating standards for excellence in clinical teaching or service as alternative grounds for tenure.

The proposed tailoring of scholarship requirements with the heavier weighting of teaching and service in tenure decisions may not be welcomed by all within the legal academy. It may even be impossible under the tenure and promotion standards at some universities. It is also recognized that within an academic culture that is already skeptical about the intellectual rigor of clinical legal education, the insistence on such tailoring 
may perpetuate the belief that clinical faculty are less capable of serious intellectual pursuit than traditional faculty members, and thus warrant a lesser role within institutional decision-making.

Despite these concerns, employment of clinical faculty on a unitary tenure track and the insistence that the standards governing hiring, retention, and promotion be responsive to the distinct characteristics of clinical legal education are grounded in the belief that the cultural differences between the academic world of scholarly productivity and the pedagogical goals and methodologies of clinical legal education are not insurmountable. To the contrary, the worlds are moving closer together, and there is much to be learned from one another.

The Task Force is encouraged in its belief by two developments. First, the experience of clinical faculty on unitary tenure tracks has demonstrated that with proper support, it is possible to balance clinical teaching and community engagement with scholarly production. The engagement of clinical faculty in scholarship, when focused on issues that are connected to clinical work, has the proven potential to enrich clinical teaching and strengthen policy and law reform work. Second, the Task Force is encouraged by the thoughtful attention that some law schools have given to the development of alternative promotion and tenure standards. These standards articulate the type and quality of written work that carries equivalent research, analysis, and academic rigor as traditional scholarship and, in some cases, allow additional weight to be awarded to excellence in clinical teaching. Together, these two developments signal a path toward mutual recognition and valuing of all members of a unitary faculty.

Moreover, although the cultural differences between the scholarly focus of the traditional tenure track and the pedagogy of clinical legal education are real, their similarities exceed their differences. All members of a law school faculty share in the common mission of legal education and carry out this mission through critical analysis of law and legal institutions, the rigorous pursuit of knowledge, and the drive to imagine possibilities beyond the status quo. Many traditional scholars on law school faculties expend time and energy on law and policy reform initiatives and on pedagogical development. This work, grounded in imagining a just world and examining the deficiencies of law and legal institutions, inform the scholarship and teaching of many members of law faculties. Traditional law teaching is increasingly evolving to include problems, simulations, and other class exercises that attempt to integrate practice skills into classroom teaching, sometimes in response to critiques of legal education, but more often because professors desire to connect with students and make their teaching more consonant with the realities of legal practice.

Like their colleagues who teach outside of clinical programs, clinical faculty employ a pedagogy that requires intellectual investment and 
mastery of one or more subject areas in law, analytical critique of law and legal systems, and critical reflection, all of which are essentially academic in nature. Although the coursework in clinical legal education is grounded in actual legal work rather than casebooks, clinical teaching requires many of the same skills of encouraging law students to abstract and generalize from particular facts and experiences to larger issues of law, lawyering, and justice. Clinical faculty regularly design teaching materials for their clinical courses that excerpt or otherwise draw on materials in academic legal scholarship. The scholarly work of clinical faculty whether expressed in law review articles, policy papers, briefs, or other materials, brings the insight of the academy to bear on the practice of law and the insights of practice into academic discourse.

The Task Force believes that over time and through experience, law school faculties will come to value the unique contributions that their clinical colleagues make to enhance faculty excellence, and that clinical faculty will continue to value the opportunity to engage in activities that demonstrate this excellence. By moving clinical and non-clinical faculty colleagues toward developing a stake in each others' worlds, a unitary tenure-track system facilitates efforts on the part of each to understand and appreciate the value and contributions of the other.

\section{ACADEMIC FREEDOM PROTECTIONS IN CLINICAL LEGAL EDUCATION}

By their very nature, many clinical courses do more than simply impart knowledge to the students in a classroom. The impact of client representation has the predictable effects of any lawyer's efforts in an adversary system. Cases can enjoin the actions of opposing or third parties, seek compensation or restitution, provide the impetus for law reform, or defend or represent controversial or unpopular clients or issues. In doing so, clinical programs invariably affect persons external to the classroom, often in ways that may not be acceptable to those persons. Because clinical programs often represent clients challenging the status quo, they may come into conflict with individuals and institutions with significant political and economic power.

As a result, clinical faculty require institutional support and protection for their academic freedom. There is agreement that clinical faculty are entitled to academic freedom, and the AALS has supported academic freedom for clinical law faculty members. ${ }^{86}$ However, this freedom has not always been respected by those outside of legal education nor clearly

86. See Statement of the Association of American Law Schools in Support of Academic Freedom for Clinical Faculty, adopted January 3, 2001 by the AALS Executive Committee. 
understood or consistently defended within the legal academy. The question is whether the external effects of clinical programs in some way justify greater oversight and control of the decisions of a clinical faculty member than of another faculty member whose teaching is confined to a classroom. And, if additional oversight or control is appropriate, schools must confront the questions of under what circumstances, to what degree, and by whom within the university that control should be exercised. ${ }^{87}$

The tensions over how far academic freedom extends are emblematic of a basic tension regarding inclusion of clinic faculty in faculty governance. Clinics that were historically run out of law schools but largely separated from a faculty governance structure enjoyed a fair amount of autonomy in decisions they made about their structure, caseload, and hiring. As clinical legal education has been included and embraced within law school curriculums and as clinical faculty have been included within faculty governance, law schools have gained a greater stake and voice in governing the affairs of clinical programs. Greater acceptance within the legal academy has provided more protection for clinical programs, but has at the same time circumscribed the autonomy of clinical programs.

The Task Force believes that most of the tensions between the newlydiscovered prerogatives of law school faculty to exercise control over clinical program decisions and the desire of clinical programs for autonomy from that control will recede over time. Moreover, bringing clinical faculty members into the ranks of tenured faculty will facilitate the communication necessary to resolve those tensions.

\section{E. CLINICAL FACULTY AND GOVERNANCE RIGHTS}

Another tension arises in the fear of the perceived impact of having clinical faculty vote on governance matters. Underlying the resistance of some to fully incorporating clinical faculty into governance - especially over issues of hiring, retention, promotion, and curriculum - is the fear that clinical faculty may vote as a bloc to wield more proportionate power in faculty meetings. Whether this fear is well-founded is open to serious question, both in terms of the proportionate number of clinical faculty members and whether they have a higher propensity to vote in blocs when compared to other members of the faculty.

However, to the extent that clinical faculty bring different perspectives to issues of the law school's mission, function, and direction, the greater harm comes in denying those perspectives a voice and a vote within a faculty governance structure. The absence of clinical faculty voices is particularly regrettable in light of current efforts at curricular integration of

87. For a more detailed discussion of these issues, see Kuehn \& Joy, supra note 71. 
clinical methods and pedagogy that many schools have undertaken, including some of the same schools which continue to disallow meaningful clinical faculty input.

The denial of governance rights raises the unavoidable inference that only traditional tenure-track faculty members have the expertise or institutional investment to govern a law school and to decide matters involving its educational mission. This Task Force rejects that proposition. As discussed above in the explanation of our core principles, the expertise rationale for diminishing the governance rights of clinical faculty, especially over issues of faculty hiring, retention, and promotion, is flawed in its assumptions. It is too often applied irrationally to clinical faculty while posing no barrier to judgments by academic faculty about clinical hiring, retention, and promotion.

\section{F. HIERARCHIES WITHIN A CLINICAL PROGRAM}

In most schools, clinical programs are staffed by faculty with different statuses. It is not unusual to see a tenured clinical faculty member working side-by-side with a colleague hired under a non-renewable short-term contract. These multi-tiered statuses have arisen in part from the success of clinical legal education as the rapid growth of clinical programs necessitated the hiring of many new clinical faculty members, not all of whom could be supported at the same time on a unitary tenure-track or other presumptively permanent status.

The tiered status within a program violates the ethos of equality that animates this Report's recommendations. Where a law school creates different statuses among clinical faculty, such tiered hiring can result in a second class status for some clinical teachers and undermine clinical faculty collegiality. Furthermore, some have experienced adverse impacts from such status differences. Lower-tiered clinical faculty have reportedly been vulnerable to marginalization within their clinical programs. Where this happens, morale and work ethic can be adversely impacted.

On the other hand, multiple statuses within clinical programs may enable the expansion of clinical opportunities for students and, in turn, service to more clients. The Task Force has addressed this concern with the recommendation that short-term contract and clinical fellowship positions be used in limited number and duration, tailored to the purpose they are designed to serve. With this recommendation, a limited hierarchy will remain. However, it will do so in the context of having a predominant core of clinical faculty members who, by their status and influence, are fully incorporated into the law school faculty. Moreover, our recommendations include the requirement that persons hired on short-term or clinic fellowships be provided the support they need to contribute 
effectively to a clinical program in which they do not have a long-term investment and to advance their own careers.

\section{GOOD PRACTICES FOR HIRING, PROMOTION, AND RETENTION OF CLINICAL FACULTY}

It is important that law schools make informed choices about their clinical programs as they advance clinical faculty toward integration and equality with non-clinical faculty. The Task Force acknowledges that its recommendation that law schools tailor faculty hiring and tenure standards to the different methodologies and responsibilities of clinical teaching poses a challenge to traditional practices, which are historically fashioned around a different mix of teaching, scholarship and service obligations. The Task Force further recognizes that schools may continue to employ other models, such as clinical tenure-track or long-term contract, which meet current ABA standards for accreditation, even though they fall short of the recommendations of this Report. To ensure that the status models discussed in this Report are implemented in ways that facilitate continued forward movement, Part IV provides recommendations for good practices to help law schools make the best use of the models or mix of models they envision implementing or currently employ.

\section{A. CLINICAL FACULTY UNDER A UNITARY TENURE-TRACK $M O D E L$}

Although the traditional tenure track is a well understood status within the legal academy, its application to clinical faculty continues to raise questions surrounding whether and how to account for their distinct methodologies and responsibilities. The success of clinical faculty on unitary tenure tracks under the same standards as non-clinical faculty is a testament to the ability of clinical faculty to succeed in legal academia and contribute as full members in faculty governance. However, to require that clinical faculty meet standards that have been fashioned around different teaching and service responsibilities does not reflect full equality, because it requires clinical faculty to be everything that traditional faculty members are and more. To account for and take full advantage of the differences in clinical teaching and service, law schools should implement standards for hiring, promotion, and retention that reflect the practice responsibilities and methodologies of clinical legal education. Here, the Task Force sets forth some suggestions for good practices for hiring clinical faculty, evaluating their performance for purposes of retention and promotion, and supporting them in their work. 


\section{Hiring on a Unitary Tenure-Track}

Full recognition and valuing of the unique methodologies and responsibilities of clinical legal education begins with the faculty recruitment and hiring process. When hiring clinical faculty onto a unitary tenure track, law school appointments committees should include members of the clinical faculty who have a full understanding of clinical teaching methods and community service obligations. Deference should be given to the assessments and opinions of other clinical faculty members who may be co-teaching with or sharing a caseload with clinical faculty candidates.

In assessing the backgrounds of clinical faculty candidates, attention should be given to their experience in the relevant practice area and their potential for connecting to and functioning well within the local legal community. Because there are multiple goals for clinical legal education, there may be different profiles that signal success in different types of clinical programs. Clinical programs with a strong social justice commitment may favor candidates with a proven background and commitment to public interest law, prominence or accomplishment in a particular area of practice or policy, or deep ties to the local bar or community. Clinical programs that wish to encourage traditional law review scholarship may look for candidates who demonstrate the promise of being able to abstract and theorize from practice. Because good clinical teaching depends in large part on the ability to develop relationships with students, community members, the legal community, and leaders of the bench and bar, and provide effective feedback to students one-on-one, faculty members should be given opportunities to assess the abilities of candidates in these areas.

\section{Evaluation and Promotion on a Unitary Tenure-Track}

Some law schools have developed standards that have been specially tailored to evaluate the teaching, scholarship, and service of clinical faculty. At some law schools where tenure standards must fit a framework required by the larger university system, these tailored standards may not be fully feasible. Nonetheless, such standards can provide useful guidance on how to implement tenure standards for clinical faculty on a unitary tenure track.

In evaluating the scholarship of clinical faculty, law schools should encourage and reward scholarly endeavors that arise from and support work in the clinical program. In sending traditional law review scholarship out for external peer review, law schools should seek reviewers with clinical background and experience as well as traditional scholars in the clinical faculty member's field. Law schools should also recognize the 
importance of clinical pedagogical scholarship and seek external peer evaluation of whether a clinical faculty member's scholarship makes an important contribution to this field by addressing issues of clinic teaching or clinical program design with originality, depth, and mastery of the field of clinical pedagogical scholarship. Recognizing that clinical teaching has unique time and energy demands that generally do not diminish upon repetition of a clinical course, tenure standards might also require a lesser quantity of traditional law review scholarship than is expected of faculty members who teach solely in classroom or seminar settings.

Credit toward tenure should also be given for the production of written materials that require originality, depth, rigor, and make important contributions to the development of law, policy, or legal education. Such works might include clinical teaching materials that usefully integrate substantive law with practice and lawyering skills, provide a critique of law and legal systems, or do both. They might also include advocacy or policy work such as briefs, policy papers, legislative advocacy materials, continuing legal education or training materials prepared to educate members of the bar, or educational materials designed for pro se litigants or members of the public. Credit might also be given for conference presentations that demonstrate knowledge, creativity, and originality.

Law schools should consider giving heavier weight to excellence in clinical teaching as part of the overall package of teaching, scholarship, and service that clinical faculty present for promotion and tenure. In evaluating excellence in clinical teaching, law schools should develop systems of peer and student evaluation that examine all aspects of clinical teaching, not simply its classroom component. Schools should recognize that some of the most important teaching occurs in one-on-one settings like individual or team supervision. If sitting in on an individual supervision session seems too intrusive and likely to change the dynamics, schools might explore the possibility of taping individual supervision sessions for review. If nonclinical faculty members sit in on clinic seminars or supervision sessions where clinic cases are being discussed, the clinical program should do appropriate conflict checks and have faculty members sign a confidentiality agreement so that client interests are not compromised.

In evaluating service, law schools should place considerable weight on the quantity and quality of a clinical faculty member's service outside the law school, both as that work contributes to the advancement of the law and the improvement of legal services in the community. Because community engagement keeps clinical faculty conversant on emerging issues and opens doors to new learning opportunities for students, excellence in service outside the law school should be understood as an essential component of an excellent clinical program. Many clinical faculty devote substantial time to developing and maintaining good 
relationships with judges, members of the bar, and local legal service offices and advocacy groups. These relationships benefit law schools by providing important links with alumni and donors and enhancing the image and reputation of the law school among practitioners and judges. To the extent that such service takes away time and energy that might otherwise be put toward the production of scholarship, the investment in public service should be recognized as having benefits to the school and be valued accordingly in the tenure process.

\section{Support for Clinical Faculty on a Unitary Tenure-Track}

Law schools should ensure the success of clinical faculty members on a unitary tenure track by extending to them the same benefits of research assistance, release time, conference travel, and library support that other tenured and tenure-track faculty enjoy. Schools also need to confront the case-related demands of clinical teaching that may impinge on the time that clinical faculty can devote toward scholarly production. Several strategies can assist clinical faculty manage their time in ways that promote success on the tenure-track.

Law schools should recognize that some types of clinic program design demand more of clinical faculty than others. For example, it often requires more time and energy to teach new clinic students than it does to teach continuing clinic students. Hence, teaching a one-semester clinic twice during an academic year is likely to be more time-intensive than teaching a two-semester clinical course. Likewise, the amount of time spent in clinical teaching increases with each additional student and with the number of credits for which students enroll. As a clinical course expands to take more students and enroll them for more credit hours, the clinic must take more clients and cases, and clinical faculty must spend more time in one-on-one supervision.

In field placement programs, clinic faculty do not have the same responsibilities and teaching duties regarding cases, but they typically have a significantly larger number of students and have the additional roles of recruiting, training and supporting placement supervisors, advising students about placement selections, and teaching to students practicing in diverse areas of law and contexts.

The practice of co-teaching clinical courses can help expand clinic slots for students as well as alleviate some of the demands on each faculty member's time, because it permits co-teachers to share responsibility for the preparation of course materials and seminar teaching. It also permits them to cover each other's cases. Co-teaching also helps to spread the responsibilities of developing and maintaining relationships with important members of the legal community and to field requests for involvement on 
boards and committees, engagement in community education, networking, organizing, or advocacy work. Co-teaching also permits staggering teaching responsibilities among co-teaching colleagues to provide research leave time. While some of these benefits can be realized by co-teaching with clinic fellows or other short-term employees, the fullest benefits of coteaching are realized when it occurs among members of the full-time clinical faculty with longer-term teaching experience and investment in the community.

Finally, attention should be paid to developing systems for covering cases and projects during summers and other class breaks that relieve clinical faculty of responsibility for their clinical work. The unpredictable timing and ongoing responsibilities of legal representation do not fit neatly within the parameters of an academic calendar. After cases are filed, unexpected developments and court schedules may control the timing and pace of resolution. The result is that cases often extend into winter and summer breaks, and with them the ethical demands on a clinical faculty member's time and attention. Law schools have addressed this concern by hiring attorneys or law student interns to cover cases during summer breaks and by establishing co-counsel relationships with attorneys on cases.

\section{B. CLINICAL FACULTY UNDER A CLINICAL TENURE-TRACK $M O D E L$}

Although the Task Force ultimately recommends against predominantly employing clinical tenure-track in lieu of unitary tenuretrack faculty, there are features of the clinical tenure-track model that are beneficial. Both clinical tenure-track and long-term contract models with presumptively renewable contracts provide the promise of some security in position. The promise of longevity and relatively stable job security of clinical tenure helps attract qualified candidates, cultivates an experienced teaching faculty, develops strong synergistic relationships over time with the community, bench, and the bar, and encourages experimentation in the classroom and the field. To the extent that law schools find it more appropriate to employ a clinical tenure-track model, the Task Force recommends some good practices to maximize the benefits that can be derived from this model, while minimizing its detriments.

An important contribution that the clinical tenure-track model has made to the legal academy is the development of clinical program-specific standards for tenure and promotion. These clinic-specific standards often reflect a thoughtful regard and studied appreciation by law schools of the value of clinical faculty and the special and significant contributions they make to law students, the law school, and the community-at-large. That these standards enunciate an expectation of excellence in all academic 
activities further dignifies these positions and attracts candidates whose experience and aptitude can elevate the quality of a school's program. Schools considering a clinical tenure-track model should follow the example of schools that have thoughtfully developed successful clinical program-specific standards for clinical tenure and promotion.

Once the standards for clinical tenure are articulated, law schools must give the same careful thought to supporting clinical faculty under these standards as they do to ensuring the success of faculty under a traditional tenure track. If scholarly production is required for promotion and clinical tenure, schools must provide the necessary support in terms of research assistance, leave time, conference and travel funds, and library support so that these faculty members can fulfill those requirements. The fact that written products considered for the tenure of clinical faculty may differ from traditional law review scholarship does not alleviate the need to support the scholarly endeavors of clinical faculty.

The greatest shortcoming in clinical tenure-track positions is that to some they create a justification, though fallacious, for denying clinical faculty a voice and a vote in important matters of faculty governance. The most notable failure is the exclusion of clinically tenured and tenure-track faculty members from voting on the hiring, retention, and promotion of faculty members on the academic tenure track. It is imperative for schools employing a clinical tenure-track model to confront these inequities and seek to eliminate them.

Because hiring decisions necessarily implicate the distribution of resources within an institution and express institutional values and priorities, the extension of governance rights over all hiring decisions is especially important. It is often possible to extend voting on appointments widely without disrupting underlying university rules or systems for promotion and tenure. Where it is not possible because of external rules to extend voting rights on matters of faculty hiring, law schools should affirmatively seek input from non-voting members of the clinical faculty on hiring decisions by including them as non-voting members on appointments committees, and by encouraging them to attend hiring meetings and voice their opinions about hiring decisions.

Where clinical faculty members are not permitted to play a part in promotion and tenure decisions of non-clinical faculty, reciprocal deference and respect should be extended on matters of the promotion and tenure of clinical faculty. For example, voting on the tenure and promotion of clinical faculty in such cases should include (if not be limited to) all members of the tenured clinical faculty, and deference should be given to the judgment of tenured clinical faculty in evaluating whether clinical tenure candidates have met the standards for clinical tenure. Voting rights on the promotion and tenure of clinical faculty should not be extended to 
pre-tenure non-clinical faculty members. To otherwise permit such faculty members to vote on clinical faculty so places a mark of inferiority on clinical tenure as compared to traditional tenure.

It remains the recommendation of this Report that a law school's clinical faculty be predominantly staffed with individuals on a unitary tenure track which offers full voting rights and other markers of integration and equality. The recommendations here are intended only where schools must resort to the less preferred Clinical Tenure Track model.

\section{CLINICAL FACULTY UNDER A PRESUMPTIVELY RENEWABLE LONG-TERM CONTRACT MODEL}

Although the protections for long-term contract clinical faculty are not as great as for tenure, faculty members on presumptively-renewable longterm contracts enjoy the promise of job stability and a solid opportunity to develop long-term relationships with the community, the bench, and the bar outside the law school. However, unlike tenure-track or tenured faculty, security may be conditional, and this can occasionally chill certain choices, including the selection of cases and pedagogy, and make clinic positions more vulnerable in times of budgetary shortfall. For schools that continue to utilize long-term contracts for clinical faculty, the Task Force recommends the following good practices.

To ensure programmatic stability and security of position, faculty policies should explicitly state that long-term contracts are presumptively renewable and otherwise fulfill the requirements as set forth in $\mathrm{ABA}$ Accreditation Standard Interpretation $405-6{ }^{88}$ As that interpretation dictates, presumptively-renewable long-term contracts should be for duration of five years or longer, though they may be preceded by "a probationary period reasonably similar to that for other full-time faculty, during which the clinical faculty member may be employed on short-term contracts." ${ }^{89}$ In addition, law schools should develop a "comprehensive system for evaluating candidates for promotion" on presumptivelyrenewable long-term contracts, "including written criteria and procedures that are made available to the faculty," in accordance with ABA Accreditation Standard Interpretation 405-3. ${ }^{90}$ Written criteria for advancement and promotion for long-term presumptively-renewable contracts should articulate clinical teaching, scholarship, and service

88. 2011-2012 Standards and Rules of Procedure for Approval of Law Schools, http://www.americanbar.org/groups/legal_education/resources/standards.html.

89. Id.

90. Id. 
expectations for the position and clearly identify the types of achievements that would fulfill those expectations.

As with clinical tenure positions, the law school's mandated "participation in faculty meetings, committees, and other aspects of law school governance in a manner reasonably similar to other full-time faculty members" must include participation on all faculty committees and a vote on all faculty hiring. ${ }^{91}$ If voting on tenure is limited by a university rule to members of the tenured faculty, the tenured faculty should, at minimum, seek the input of clinical faculty on presumptively-renewable long-term contracts by including them as non-voting members on hiring, retention, and promotion committees and affirmatively seeking their input on tenure decisions.

Decisions on the promotion of clinical faculty to presumptivelyrenewable long-term contracts should be considered comparable to tenure decisions in terms of the seriousness of their consequences and their effect on employees to whom the law school has made a long-term investment. Accordingly, pre-tenure members of the faculty who are not permitted to vote on the tenure of their colleagues should not be permitted to vote on the presumptively-renewable status of long-term clinical contract employees.

\section{CLINICAL FACULTY UNDER A SHORT-TERM CONTRACT MODEL}

The uncertain continuing status of short-term contracts has many disadvantages compared to the other status models. Because many cases require a long-term commitment, short-term faculty may be less inclined or equipped to undertake such cases. Moreover, because such cases often involve representing an unpopular client or cause, the "at-will" nature of short-term employment contracts sharpens a teacher's vulnerability to outside interference and decanal influence on such fundamental matters as client and case selection. The success of field placement programs is dependent on the relationships clinical faculty develop with the supervising attorneys, necessitating a long-term commitment by the institution to the faculty member. Because clinical faculty members are not permanent members of the law school faculty, and at some schools, not deemed part of the faculty at all, the absence of governance rights is almost never questioned. Thus, as a practical matter, short-term clinical faculty members have very limited opportunities to participate in law school governance, especially on matters of curriculum or personnel.

Law schools should limit the use of faculty on short-term contracts to experimental programs of short duration or specific programs financed with

91. Id. 
short-term funding. In programs where short-term contracts are the primary or exclusive model, a school may never benefit from the insights of its clinical faculty. Faculty on contracts of two or more years should be permitted to participate and vote on relevant faculty committees and on faculty governance issues that pertain to the clinical program, including clinical hiring. If a program becomes a permanent part of the academic curriculum or if funding is secured for more than three years, faculty should be awarded contracts co-extensive with the outside funding source.

To hire and retain short-term contract clinical faculty in a responsible manner, institutions must engage in periodic (such as annual) reviews of those faculty members. Evaluation standards should be explicitly set forth. Importantly, short-term contract clinical faculty should also be given mentoring, evaluation, and feedback. Clinical faculty employed on shortterm contracts should be afforded the opportunity to participate in professional development programs that expose them to clinical pedagogy, improve their clinical supervision, and enhance and maintain their lawyering skills and substantive legal knowledge. Senior and longer-term clinical faculty should mentor them in the development of case selection policies, seminar materials, and teaching and supervision techniques.

Faculty on short-term contracts, who may have recent and critical connections to social justice initiatives in the community, should be encouraged to build on those relationships as a means to enhance their teaching and the clinical program and law school's integration in broader community initiatives. Short-term contract faculty new to this particular community should be encouraged and supported in their efforts to establish relationships with others in their field outside of the law school. Faculty on short-term contracts should be provided perquisites comparable to their similarly situated clinical colleagues to the extent that those perquisites are not dictated by the terms and conditions of outside funding sources.

Clinical faculty employed on short-term contracts should not be expected to produce scholarship as part of their job requirements. If scholarship is required, it should be defined and supported in a manner that enables such faculty to produce scholarship in the context of the work they perform and the service they provide to their community and the profession.

Adjunct professors, who by definition have other employment, should be sparingly used to supervise clinical students. Adjuncts should be employed only in limited circumstances, such as in unanticipated openings in clinical teaching positions, in programs requiring unique expertise not otherwise available, or in partnership with permanent, full-time clinical faculty. 


\section{E. CLINICAL FELLOWSHIP PROGRAMS}

Clinical fellowship positions are often created to expand the number of clinical program slots available to students or to provide summer coverage for cases. Increasingly, clinical programs are designing these positions to provide training for those wishing to become clinical faculty members. The contributions of clinical fellows can enhance a program by augmenting the work of the established clinical faculty and by providing relief to clinical faculty engaged in scholarly research and writing during the summer. Moreover, clinical fellow salaries are modest when compared to those of regular clinical faculty. Thus, clinical fellowship programs often operate at a cost savings to the law school.

By their nature, clinical fellowships are short-term terminal contracts designed to provide the fellow with clinical teaching experience, the opportunity to reflect on these experiences, and possibly the prospect of being better positioned in the law school teaching market. The challenge for schools developing a clinical fellowship program is to design a structure by which fellows can accumulate experience and achievement that will assist them in procuring future appointments either at the same school or elsewhere. Because clinical fellows are terminal employees, there need not be a requirement for their formal involvement in decisions affecting the mission and direction of the law school (e.g. voting rights or committee participation). However, in structuring its fellowship programs, law schools should be explicit about the goals for the fellowship positions and have the resources and commitment to provide the necessary support for the fellows.

Because many clinical fellows want to eventually enter the academy as a career, a fellowship program should support and mentor those fellows with their teaching, scholarship, and service. Fellowship programs should be designed to permit mentorship and support for clinical teaching. A few ways to help fellows become better teachers include pairing a fellow with a committed mentor, creating meaningful opportunities for co-teaching, and instituting "supervision rounds" during which fellows and more experienced clinical faculty members can discuss teaching or supervision issues or delve into pre-assigned articles on clinical pedagogy. Clinical fellowship programs should also provide support for practice in an unfamiliar jurisdiction by providing liaisons who have established relationships in the legal community and knowledge of local practice.

If the clinical fellowship program is designed in part to help the fellow develop scholarship, law schools should provide adequate time for research and writing, as well as for the presentation and exchange of ideas, to properly equip the fellow for success in the academic job process. If fellows in such a program are expected to provide summer coverage of 
cases, they should be compensated with leave time or a teaching reduction during one or more terms.

Critically, care must be taken to avoid the exploitation of clinical fellows. If support for the fellow's career advancement is absent, the clinical fellowship may undermine rather than enhance the teaching and social justice goals of the clinical program. Clinical fellows are at a power disadvantage relative to more established clinical faculty within a clinical program itself. They often depend on senior clinical colleagues for job recommendations and networking opportunities to advance their careers. As a result, fellows may feel unable to negotiate the teaching or case coverage expectations placed upon them. Further, fellows may not feel insulated against criticism for representing unpopular clients or controversial issues and should be assured of protection by the clinical program and law school when acting in the scope of their position. Clinical programs or, where appropriate, the institution itself, should provide mechanisms for feedback and support to fellows to ensure that the terms and conditions of their own employment are fair and reasonable.

\section{CONCLUSION}

This Report is premised on the assumption that law schools are proceeding in good faith as they address the role and status of clinical faculty at their institutions, and the intention of the Task Force is to be helpful and supportive of these efforts. Where efforts have stalled, this Report is intended to inspire and inform programs into renewed thought and activity. In all cases, it is hoped that schools will strive toward the recommendations set forth in this Report and move steadily but inexorably toward providing a place for clinical faculty in the legal academy that reflects the value of clinical legal education in cultivating effective and ethical legal professionals. To achieve the mission of transforming law students into effective, ethical, and humane lawyers, the Task Force urges law schools to value and implement the core principles set forth in this Report. The Task Force recognizes that the recommendations will require a shift in visions and priorities at many law schools. However, a push toward the adoption of unitary tenure-track policies for clinical faculty will acknowledge the critical role clinical legal education must serve in the legal academy and the profession in the twenty first century. A lesser recommendation would condone the continued marginalization of clinical legal education and the suppressed voices of clinical faculty-all to the detriment of the legal academy and the legal profession. 